Portland State University

PDXScholar

\title{
A Comparison of the Time Taken to Administer and Analyze Phonologic and Phonetic Tests
}

Beverly Alexander

Portland State University

Follow this and additional works at: https://pdxscholar.library.pdx.edu/open_access_etds

Part of the Speech Pathology and Audiology Commons

Let us know how access to this document benefits you.

\section{Recommended Citation}

Alexander, Beverly, "A Comparison of the Time Taken to Administer and Analyze Phonologic and Phonetic Tests" (1989). Dissertations and Theses. Paper 3854.

https://doi.org/10.15760/etd.5738

This Thesis is brought to you for free and open access. It has been accepted for inclusion in Dissertations and Theses by an authorized administrator of PDXScholar. Please contact us if we can make this document more accessible: pdxscholar@pdx.edu. 
AN ABSTRACT OF THE THESIS OF BEVERLY ALEXANDER fOI the Master of Science in Communication presented May 9, 1989.

Title: A Comparison of the Time Taken to Administer and Analyze Phonologic and Phonetic Tests.

APPROVED BY MEMBERS OF THE THESIS COMMITTEE:

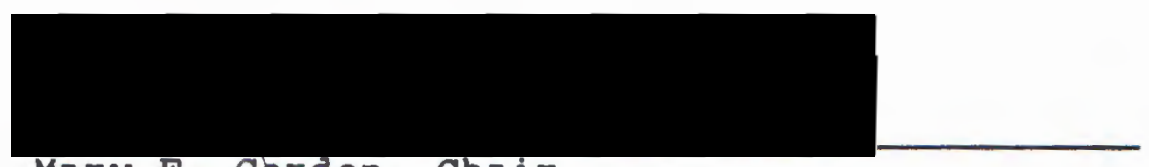

Mary E. Gordon, Chair

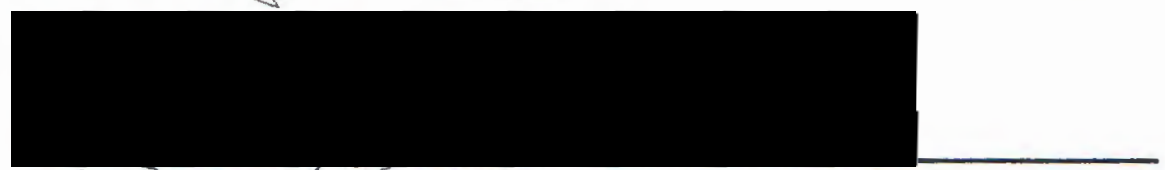

Robert Casteel

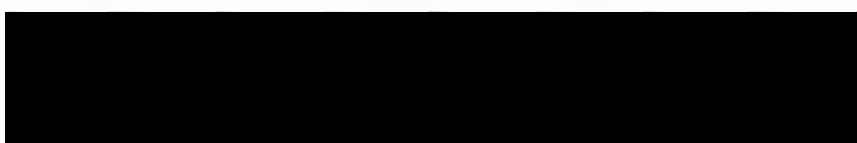

Edith Sullivan

In the past, many public school speech-language pathologists have verbalized that phonological process assessments are too time-consuming for those with large caseloads. If a phonological assessment tool can be shown to take approximately the same amount of time as a typical phonetic analysis, then perhaps public school speechlanguage pathologists would analyze and treat their phonologically-impaired clients using a more appropriate phonological approach instead of a less effective phonetic 
approach. The main postulation of using a phonological process-based approach is that remediation time is saved because generalization occurs across the entire process when only a few sound errors are treated.

In reviewing the Iiterature, statistical comparisons between the time it takes to complete (administer and analyze) a phonological analysis and the time it takes to complete a phonetic analysis were not found. This lack of data lead to the development of this study, which was undertaken in order to determine the accuracy of the clinician's perceptions that a phonologic process assessment is more time-consuming than a phonetic assessment. The phonologic process tests used in this study were the Assessment of Phonological Processes-Revised (APP) (Hodson, 1986) which was analyzed by the Computer Analysis of Phonological Processes (CAPP) (Hodson, 1985) and the Khan-Lewis Phonological Analysis (KLPA) (Khan \& Lewis, 1986). The phonetic tests used in this study were the Goldman Fristoe Test of Articulation (GFTA) (Goldman \& Fristoe, 1986) and the photo Articulation Test (PAT) (Pendergast, Dickey, Selmar, \& Soder, 1969).

The purpose of this study was to determine if the time it takes to complete a phonological test was significantly different than the time it takes to complete a phonetic test. It was hoped this study would identify an instrument that the public school speech-language 
pathologist could use more effectively and efficiently to analyze phonologically-impaired children.

Twelve subjects, ages 4-1 to 6-7 years with mild, moderate, or severe phonologic and/or phonetic disorders participated in this study. Five speech-language pathology students who had experienced at least two speech and hearing clinics at PSU, were selected as examiners for this study.

The mean $(\bar{x})$ and standard deviation (S.D.) of the completion time of each test used in this study were calculated and are as follows: APP as analyzed by the APP (APP/CAPP): $\overline{\mathbf{x}}=22: 56$, S.D. $3: 29$; the KLPA with the transcription time from the GFTA sound-in-words subtest: $\bar{x}$ $=43: 14$, S.D. $=11: 56$; the KLPA without transcription time from the GFTA sounds-in-words subtest: $\bar{x}=37: 26$, S.D. $=$ 11:01; the GFTA: $\bar{x}=26: 13$, S.D. $=4: 05$; the PAT: $\bar{x}=$ $11: 27$, S.D. $=2: 04$. Two-talled t-tests for dependent means were used to compare the two phonological tests with the two phonetic tests. The study revealed that each comparison was significantly different beyond the .05 level of confidence. The APP/CAPP takes significantly less time to complete than the GFTA. The PAT takes significantly less time to complete than the APP/CAPP and the KLPA. The GFTA takes significantly less time to complete than the KLPA. Additionally, the phonological tests were compared with each other and the results revealed that the APP takes 
significantly less time to complete than the KLPA.

The data also revealed that the more severe the child's speech sound disorder, the more time needed to complete the test. Although the number of subjects that participated in this study is limited, information gathered might be helpful in demonstrating that there are phonologic tests, such as the APP/CAPP, which are less time-consuming than some frequently used phonetic tests, such as the GFTA. 
A COMPARISON OF THE TIME TAKEN TO ADMINISTER

AND ANALYZE PHONOLOGIC AND PHONETIC TESTS

by

BEVERLY ALEXANDER

A thesis submitted in partial fulfillment of the requirements for the degree of

\author{
MASTER OF SCIENCE \\ in \\ SPEECH COMMUNICATION : \\ SPEECH AND HEARING SCIENCE
}

Portland State University

1989 
TO THE OFFICE OF GRADUATE STUDIES:

The members of the Committee approve the thesis of Beverly Alexander presented May 9, 1989.

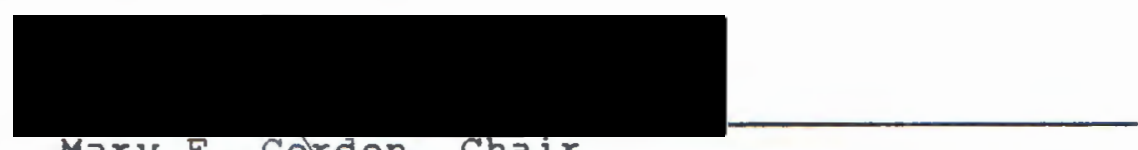

Mary E. Gordon, chair

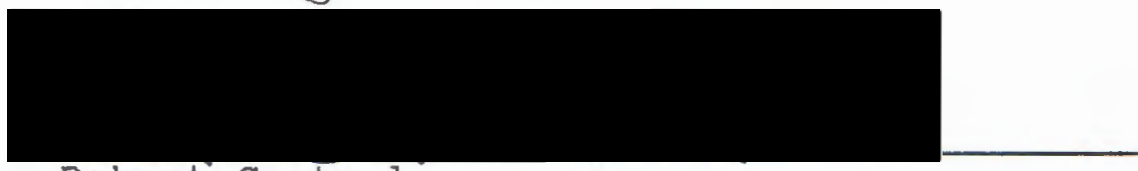

Robert Casteel

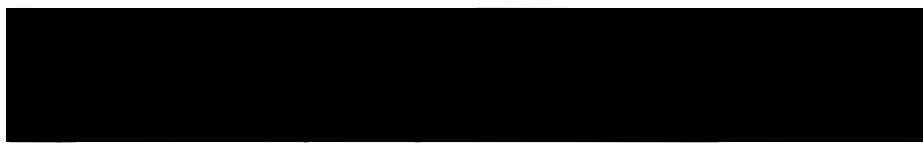

Edith Sullivan

APPROVED :

Theodore T. Grove, Chair, Department of speech Communication

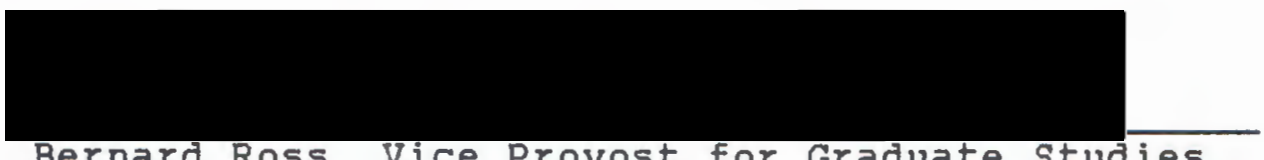

Bernard Ross, Vice Provost for Graduate studies 


\section{ACKNOWLEDGEMENTS}

I would like to acknowledge Mary E. Gordon for her guidance, flexibility, and patience throughout this project as well as graduate school.

I would like to dedicate this project to my husband, Don Alexander, who gave me the support I needed to complete this project, thank you. 
TABLE OF CONTENTS

Page

ACKNOWLEDGMENTS $\ldots \ldots \ldots \ldots \ldots \ldots \ldots \ldots \ldots \ldots$ i

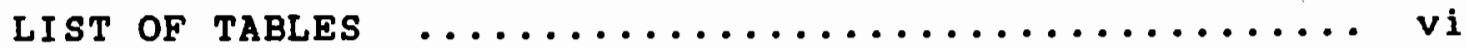

LIST OF FIGURES $\ldots \ldots \ldots \ldots \ldots \ldots \ldots \ldots \ldots \ldots \ldots \ldots \ldots \ldots \ldots$

CHAPTER

I INTRODUCTION AND STATEMENT OF PURPOSE $\ldots \ldots \ldots 1$ Introduction $\ldots \ldots \ldots \ldots \ldots \ldots \ldots \ldots$

statement of $\operatorname{Terms} \ldots \ldots \ldots \ldots \ldots \ldots \ldots$

Definition of Terms $\ldots \ldots \ldots \ldots \ldots \ldots \ldots$

I I REVIEW OF THE LITERATURE $\ldots \ldots \ldots \ldots \ldots \ldots$

Phonetic Verses Phonologic Approach ...... 7

Time Considerations of Speech Sound Tests. 15

Other Time Saving Procedures ........ 17

Validity and Reliability

of the APP and KLPA ............ 19

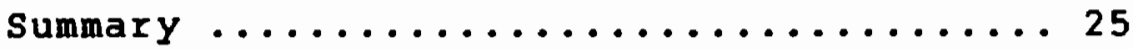

II METHODS AND PROCEDURES $\ldots \ldots \ldots \ldots \ldots \ldots \ldots$

Methods .................... 26

Procedures $\ldots \ldots \ldots \ldots \ldots \ldots \ldots \ldots \ldots \ldots \ldots$

Data Measurement And Analysis ........ 34

IV RESULTS AND DISCUSSION $\ldots \ldots \ldots \ldots \ldots \ldots \ldots$

Results ................... 36

Discussion $\ldots \ldots \ldots \ldots \ldots \ldots \ldots \ldots \ldots$ 
V SUMMARY AND IMPLICATIONS .............. 50

summary ........................ 50

Implications ......................53

REFERENCES .............................. 56

APPENDICES

A PHONOLOGICAL PROCESS DEFINITIONS USED

IN THE ASSESSMENT OF PHONOLOGICAL

PROCESSES-REVISED ................. 60

B PHONOLOGICAL PROCESS DEFINITIONS IN THE

KHAN-LEWIS PHONOLOGICAL ANALYSIS ....... 62

C PARENTAL CONSENT FORM ................ 65

D EXAMINER'S QUESTIONNAIRE ............... 68

E OUTLINE OF INFORMATION COVERED

IN TRAINING PERIOD ................ 7 I

F EXAMINER'S TIMING PROCEDURES AND

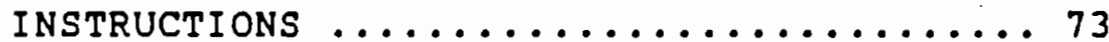

G THE RECORDING FORM FOR THE ASSESSMENT

OF PHONOLOGICAL PROCESSES-REVISED ...... 76

H COMPUTER PRINT OUT OF THE COMPUTER

ANALYSIS OF PHONOLOGICAL PROCESSES ...... 78

I CHART TO RECORD TIMED RESULTS ............ 80

$J$ TOTAL OF THE ADMINISTRATION AND ANALYSIS

TIMES FOR THE APP/CAPP, KLPA, GFTA,

AND PAT .......................... 82 


\section{LIST OF TABLES}

TABLE

PAGE

I Order of Three Tests Administered ........... 33

I I Means, Standard Deviations, Ranges, and

t-Test Comparisons For Phonologic Versus

Phonetic Completion Times ......................

II Means Standard Deviations, Ranges, and

$t$-Test Comparisons For the APP/CAPP Versus

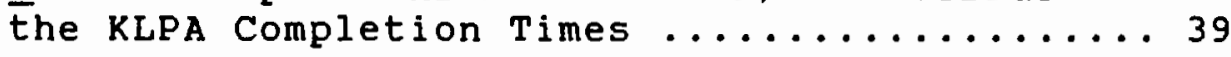

IV Positive and Negative Attributes of Tests .....4 41 


\section{LIST OF FIGURES}

\section{FI GURE}

1. Alternative Views of the Terms "Articulation" Disorders Versus "Phonologic" Disorders ....12

2. Model and Replica Chart .................

3. Mean Completion Times According to the Child's Severity Level ..................40 


\section{CHAPTER I}

INTRODUCTION AND STATEMENT OF PURPOSE

\section{INTRODUCTION}

Many experts in the area of speech sound disorders stress the need to consider phonological processes, as well as individual phonemes, when assessing children with articulation disorders (Dunn \& Barron, 1982; Edwards, 1983; Hodson \& Paden, 1983). This emphasis is directed toward improving the efficiency and effectiveness of remediation, but some speech-language pathologists are still not using a phonological process approach in the assessment and/or remediation process. Schwartz (1988) administered a survey regarding phonological processes to public school speech-language pathologists in oregon, and found that 518 contended that phonologic process analysis is too time-consuming to be used in the public schools.

It is well known that many public school speech-language pathologists are overly burdened with large caseloads and must use their management time wisely. If a phonological assessment tool that takes approximately the same amount of time as a typical phonetic analysis can be utilized, then perhaps public school speech-language pathologists will begin to analyze and treat their 
phonologically impaired clients using a more appropriate phonological approach instead of a less effectlve phonetic approach .

The Assessment of Phonological Processes-Revised

(APP) (Hodson, 1986 ) uses 50 3-dimensional objects to elicit spontaneously produced, one-word responses for assessment. It is one of the faster phonological tests to administer, but analysis of the transcribed results is quite time-consuming (Weiss, Gordon, \& Lillywhite, 1987). In 1985, Hodson published a computer program called Computer Analys is of Phonological Processes (CAPP) for the purpose of saving clinicians time in analyzing the APP.

The Khan-Lewis Phonological Analysis (KLPA) (Khan \& Lewis, 1985) is another widely-used phonological process assessment tool. It is designed to be used with the responses obtained on the Goldman-Fristoe Test of Articulation (GFTA) (Goldman \& Fristoe, 1986). The responses from the test can be analyzed for phonetic and phonologic errors, the latter through the KLPA analys is form.

From this researcher's experience, the KLPA requires much more time to analyze than other articulation assessments. However, a benefit of using the KLPA with the GFTA is the clinician can do a phonetic analysis as well as a phonologic analysis when only one test is administered. As with many diagnostic tests, when a shorter and 
quicker version is used, less information results when compared to a longer, more thorough test (Andrews \& Fey, 1986; Dyson \& Robinson, 1987). A time-consuming analysis is not realistic for the public school speech-language pathologist who needs to develop a large number of individualized educational plans within a short period of time. Speech-language pathologists may also need to submit standardarized test results to prove the existence of an articulation disorder (Klein, 1984). The percelved problem of a phonological process assessment being too time-consuming raised the following purpose statement and experimental question.

\section{STATEMENT OF PURPOSE}

The purpose of this study was to determine if the time it takes to administer and analyze (complete) a phonological test is significantly different than the time it takes to complete a phonetic test. specifically, the APP as analyzed by the CAPP, (APP/CAPP) and the KLPA were compared with the photo Articulation Test (PAT) (Pendergast, Dickey, Selmar, \& Soder, 1969) and the GFTA. Hence, this study sought to answer the following question: Is the time it takes to complete phonological assessments, i.e., APP/CAPP and KLPA significantly different than the completion time of phonetic tests, i.e., PAT and GFTA? This in turn led to the following null 
hypotheses: The completion time of the APP/CAPP and/or the KLPA is not significantly different than the completion time of the GFTA and/or the PAT. Additionally a corollary question was asked: Is the time it takes to complete the APP/CAPP significantly different than the completion time of the KLPA? The purpose of answering these questions was to identify an instrument that the public school speech-language pathologist can use more effectively and efficiently to analyze phonologically disordered children in the limited amount of time avallable to them.

\section{DEFINITION OF TERMS}

The following definitions were utilized throughout this study.

Phonetic Assessment/Analysis: phonemic assessment which describes phonetic errors in terms of omission, substitutions, and distortions; each speech sound is analyzed according to its position (initial, medial, and final) (Weiss, Gordon, \& Lillywhite, 1987).

Phonetic Disorder/Impairment: occurs when a child has not learned the correct motor movements reguired to achieve acceptable productions of speech sounds (Schwartz, 1983). Phonologic Assessment/Analysis: speech sound assessment which describes errors according to phonological patterns or processes. "These error patterns frequently affect entire sound classes, particular sound sequences, or the 
syllable structure of the word" (Bernthal \& Bankson, 1988, P. 2651

Phonologic Disorder/Impairment: occurs when a child has not learned the correct linguistic rules required to achieve acceptable productions of speech sounds (schwartz, $1983)$.

Phonologic Processes: describe the alterations between the sounds actually produced and the adult target production (Welss et al., 1987).

Speech Sound Disorder/Impairment: occurs when a child produces speech sound errors not typically present in their normally developing peer group (Schwartz, 1983). The following acronyms will be utilized throughout this study. This list will give the reader a quick reference guide of unfamiliar acronyms used.

APP: Assessment of Phonologic Processes-Revised (Hodson, 1986); an articulation test which is used to assess phonologic errors.

APP/CAPP: Assessment of Phonologic Processes (Hodson, 1986) analyzed by the Computer Assessment of Phonological Processes (Hodson, 1985).

CAPP: Computer Assessment of Phonological Processes (Hodson, 1985); a computer program which analyzes results from the APP.

GFTA: Goldman-Fristoe Test of Articulation (Goldman \& Fristoe, 1986); an articulation test which is used to assess phonetic errors. 
KLPA: Khan-Lewis Phonological Analys is (Khan \& Lewis, 1986); an articulation test which analyzes phonologic errors.

NPA: Natural Process Analys is (Shriberg \&wlatkowski, 1980); an articulation test which is used to assess phonologic errors.

PAT: Photo Articulation Test (Pendergast et al., 1969); an articulation test which is used to assess phonetic errors. PPACL: Procedures for the Phonological Analysis of Children's Lanquage (Ingram, 1981); an articulation test which is used to assess phonologic errors. For definitions of phonological process terms, refer to Appendices $A$ and $B$. 


\section{REVIEW OF THE LITERATURE}

Phonologic process analysis and phonetic analysis are the two main approaches used by speech-language pathologists for assessing speech sound disorders. This chapter will begin by discussing the basic differences between these two approaches and the history behind the controversy of describing speech sound disorders. The administration and analysis times of tests being used in this study and other time-saving phonological process assessments will then be considered, followed by a discussion of the reliability and validity of the KLPA and the APP.

\section{PHONETIC VERSUS PHONOLOGIC APPROACH}

There are distinct differences between phonetic and phonologic approaches. Below is a discussion of the differences.

\section{Phonetic Approach}

One of the earliest approaches for treating and assessing speech sound disorders, and still commonly used today, is the "traditional" approach developed by van Riper 
In the 1950's (Elbert \& Geirut, 1986). This phonetic approach is a phonemic assessment which describes phonetic errors in terms of omissions, substitutions, and distortions; each speech sound is analyzed according to its position (initial, medial, and final) in the word (Weiss et al., 1987).

Schwartz (1983) described a phonetic error as an organic deviancy which effects the motor ability to produce a sound of speech because there are limitations of the person's speech mechanism. Bernthal and Bankson (1988) explained that phonetic errors occur because the "ability to produce a target sound is not within the person's repertoire of motor skills" (p.3). Phonetic errors usually have an organic cause, e.g., cleft palate, hearing impairment, and neurological disturbances (Schwartz, 1983), but can also be associated with unknown or nonorganic sources (Weiss et al., 1987). Phonetic errors are generally consistently produced, i.e., they are seldom, if ever, produced correctly in any position, e.g., /s/ is always misarticulated in the initial, medial, and final position in all words containing /s/ (Paul, 1988). Examples of phonetic analysis tests commonly used today include the Arizona Articulation Proficiency scale (Fudala, 1970), the Developmental Articulation Test (Hejna, 1963), the GFTA, the PAT, and the remplin-Darley rests of Articulation, (Templin \& Darley, 1969). Remediation of 
phonetic disorders should probably focus on the actual motor production of the speech sounds (Paul, 1988).

\section{Phonologic Approach}

The most recent approach to the assessment of speech sound disorders, which was developed in the late 1960's, is phonological process analysis. This interest in assessing speech sound disorders according to phonological processes is credited to stampe (Elbert, Dinnsen, \& Weismer, 1984). This phonologic approach is a speech sound assessment which describes errors according to phonological patterns or processes (See appendices A \& for examples of some of these processes). These patterns or processes are errors that occur when a child has not learned the correct linguistic rules required to achieve acceptable productions of speech sounds (Schwartz, 1983). "These error patterns frequently affect entire sound classes, particular sound sequences, or the syllable structure of the word" according to Bernthal and Bankson (1988; p. 265).

Phonological errors are usually due to "functional" causes. They are inconsistently produced depending on linguistic context and quality of other sounds surrounding the error sound. They are patterned errors, e.g., the error could occur across back consonants (Schwartz, 1983), and the misarticulation is usually easier to generate than the adult target sound (Weiss et al., 1987). These 
children are much more likely to have a combined language disorder. The idea of identifying children's systematic speech sound error patterns by phonological process analysis has resulted in many assessment manuals (Elbert et al., 1984), including the APP, KLPA, Natural Process Analysis (NPA) (Shriberg \& Kwiatkowski, 1980), Phonological Process Analys is (PPA) (Weiner, 1979), and Procedures for the Phonological Analysis of Children's Language (PPACL) (Ingram, 1981).

Remediation for these children should probably focus more on the phonologic process used in error to facilitate the emergence of new sound patterns rather than the actual motor movement of the individual speech sound (Compton, 1976; Paul, 1988).

The main postulation of using a phonological process-based approach in treating children with a speech sound disorder is that remediation is maximized due to the generalization which occurs across the entire process when only a few sound errors from the specific process are treated (Compton, 1976). Many studies have been completed which support this remediation approach (Crary \& Hunt, 1983; Dunn \& Barron, 1982; Elbert, 1983; Hodson, 1983; Tyler, Edwards, \& Saxman, 1987).

Hence, by using a phonological process approach in remediation, time would be saved because generalization occurs across the entire process when only a few sound 
errors are treated. Although there have been no empirical data to support this hypothesis (Tyler et al., 1987) many researchers (Edwards, 1983; Hodson \& Paden, 1983; \& Tyler et al., 1987) support the ldea that it can save remediation time. This postulation gives additional support to this study. If a child is assessed using a phonological process analysis and thus treated using a phonological approach, then time could be saved during treatment.

\section{Which Term Should Be Used?}

There is some confusion in the labeling of speech sound errors because both phonetic and phonologic errors have been described by more than one name, and at times have been given more than one meaning. Bernthal and Bankson (1988) explained that the motorically based errors have been labeled phonetic errors and/or articulation errors. The "cognitively or linguistically-based" errors have been termed phonological errors and/or phonemic errors.

Shriberg (1986) attempted to clarify some of this confusion by explaining the history of these terms (Figure 1). The word dyslalla, which is defined as "defective articulation due to faulty learning or to abnormality of the external speech organs and not to lesions of the central or peripheral nervous system" (Wood, 1971, p. 86) was replaced with the label, articulation, approximately in the year 1920 . 
The word articulation was used for all speech sound disorders between 1920 to 1970 . In the 1970 's, a second method of analyzing speech sound disorders was introduced. This method analyzed the errors phonologicaliy or according to their linguistic base. This new analysis procedure created some controversial issues. Clinicians questioned the efficiency of this lengthy and complex analysis as well as whether children could actually be analyzed more accurately using this procedure. At that point, articulation was the main term utilized to describe speech sound errors (shriberg, 1986).

Beglnning in the 1980's, the term phonology was becoming a more widely utilized term. This was possibly

ARTICULATION VS PHONOLOGY

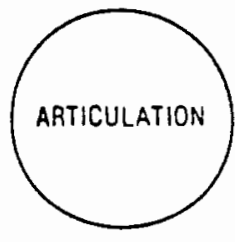

"ARTiculation"

$1920-1970$

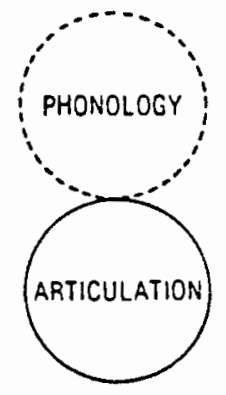

"ARTICULATION AND PHONOLOGY"

$7970-1980$
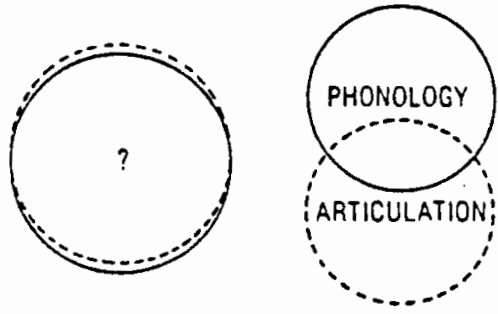

"ARTICULATION. PHONOLOGY"

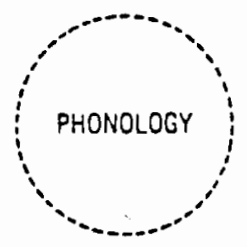

"PHONOLOGY"

\section{$1980-7985$}

Fiqure 1. Alternative views of the terms "articulation" disorders versus "phonologic" disorders. (From: Shriberg, L.: Programs to Examine Phonetic and Phonologic Evaluation Records, University of Wisconsin, Software Development and Distribution Center, 1986, p. 11). 
due to the increase of 1 ts presence in the literature, the education of future clinicians, and possibly because of the increase in the avallability of phonological analysis procedures (Shriberg, 1986).

Presently, some clinicians continue to use the two terms synonomously, which is shown in Figure 1 by the circles with the question mark. Others recognize three speech sound disorders, the two primary disorders and a third which is a combination of both (shown by the overlapping area). The solid line around the term phonology versus the dotted line around articulation signifies that this term now appears more frequently in the literature as headings and chapter titles (Shriberg, 1986). The last symbol to the far right, in Figure 1, suggests the possiblity that the term "phonology" is a better word than "articulation," when discussing the general topic of speech sound disorders. The dotted ine, around the word "phonology," signifies that "relevant terminological issues are, to date, unresolved" (shriberg, 1986, p. 13).

TIME CONSIDERATIONS OF SPEECH SOUND TESTS

In reviewing the 1 iterature, statistical

comparisons between the time it takes to analyze and administer a phonological analysis and the time it takes to analyze and administer a phonetic analysis were not 
found. Although there seemingly have been no comparative stuaies completed, test manuals and articles do estimate the approximate time required to administer and score the tests being used in this study, but most authors did not give specific data on how many subjects were timed nor the examiner's qualifications.

Pendergast et al. (1969) stated the PAT, a phonetic analys is test, takes approximately 5 minutes to administer, but they do not specify the analysis time. Welss et al. (1987) reported that the entire procedure takes approximately 20 minutes. Goldman and Fristoe (1986) did not 1 ist the administration or the analysis times of the GFTA. Weiss et al. (1987) reported that the adminstration time is approximately 20 minutes, and Bernthal and Bankson (1988) stated 1t takes 10 to 12 minutes to administer. None of the authors gave an estimation of the analysis time nor conditions of the timing.

In looking at phonological tests, Hodson (1986) reported the APP takes 15 to 20 minutes to administer and the analysis takes 30 minutes. She also reported that an experienced clinician with good phonetic skills can complete the entire procedure in less than one hour. Hodson (1985) stated that by using the CAPP program to analyze the APP, the analysis time is decreased to 10 minutes. Paden and Moss (1985) calculated the mean time required to complete the PPACL (a subtest only), the NPA, 
and the APP. The results indicated the PPACL subtest takes 3 hours and 46 minutes; the NPA, 2 hours and 1 minute; and the APP, 59 minutes. The only examiner qualifications specifled were that they must have thoroughly famlliarized themselves with the three tests prior to giving them. since the APP took the least amount of time, these results indicate a reason for it to be one of the most desirable phonological tests when considering the factor of efficiency.

Khan and Lew1s (1986) reported that the KLPA, phonological process test, takes 15 to 40 minutes "to complete". They do not describe any of the conditions present in obtaining this time estimate.

As can be seen from the above reports, most of the times for test administration and analysis were approximated or not reported. Additionally no data were provlded as to the number of subjects timed, severity of the subjects, or the qualifications of the examiner.

\section{OTHER TIME SAVING PROCEDURES}

Some researchers have recognized the need for a less time-consuming phonological process assessment for the public school speech-language pathologist. Klein (1984) suggested a step-by-step procedure which converts the results from any "popular" articulation test (1.e., phonetic analysis) into a phonological processes analysis. 
This six-step procedure is an attempt to reduce the time it takes to administer and analyze a phonological assessment, and a way to use a traditional test for a phonologlcal process analysis. This is accomplished by the evaluation of each consonant in every test word by charting each attempt of a consonant target within the Model and Replica chart (Figure 2). The chart displays the consonants elicited from an articulation test according to word position, place, and manner of articulation. Target consonants for English are represented by the symbol given in the upper left corner of each box as shown in Figure 2 . The Model and Replica Charts are used as a preliminary analysis. Since the one-word test eliminates the need to administer an additional phonological test, it appears to be a time-efficient means for assessing children with phonologically impaired processes, but the time it saves has never been determined.

Garn-Nunn (1986) developed a procedure to save tIme by administering conventional articulation tests and analyzing them phonologically. Each test is fully transcribed and then every process affecting any test-word phoneme is identified. This procedure saves time because it is not necessary to administer an additional phonological test, but the author implied time is not saved durlng analysis and the clinician needs to be very familiar 


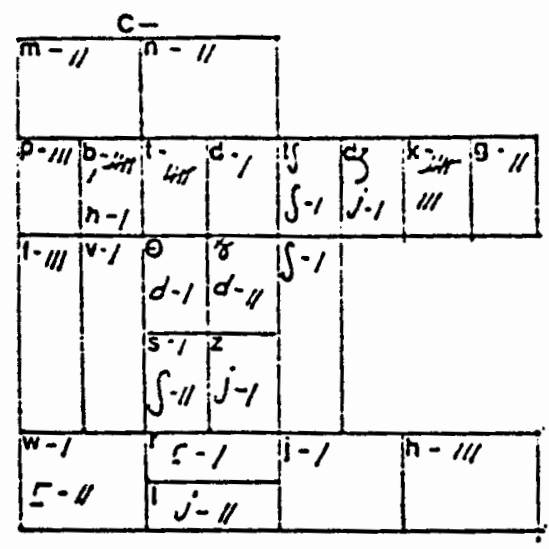

cluslaes

$s p \rightarrow b \cdot:$

$s x \rightarrow a \because$

$5 t \rightarrow g^{3} \cdot 4$

bl $\rightarrow r-1$

$k \prime \rightarrow S-1$

$f l \rightarrow f-\| l$

$b r \rightarrow v r-1$

$k r \rightarrow v r-1 ; f-1$

$t r \rightarrow \bar{F} \cdot /$

$S_{W \rightarrow F}-1$

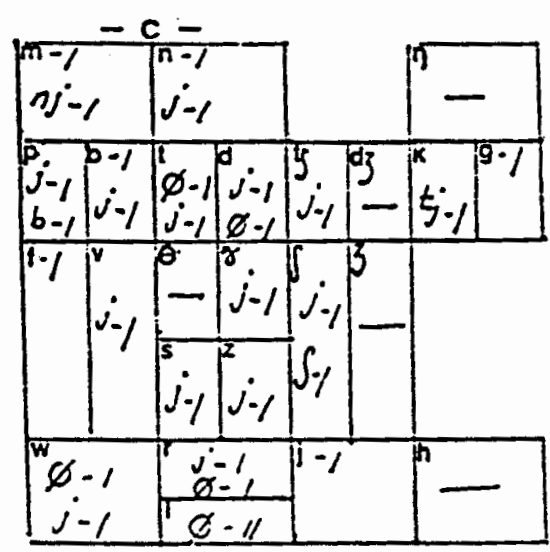

clusters

$\begin{array}{ll}n s \rightarrow n j & \theta b r \rightarrow w . \\ s t \rightarrow g_{\phi} & \partial^{k} \rightarrow n_{j} \\ n w \rightarrow n_{j} & \partial_{j} \rightarrow n_{j} \\ n d_{j} \rightarrow n_{j} & \end{array}$

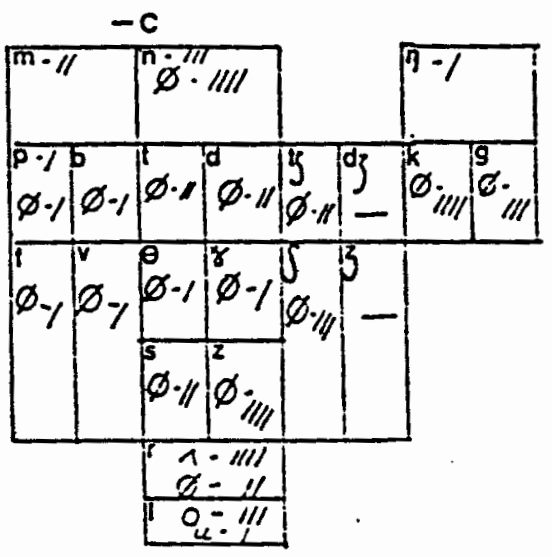

clusiers

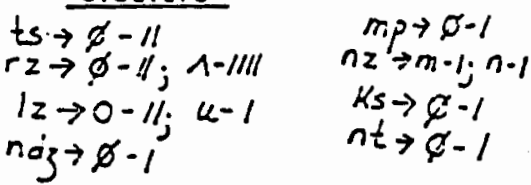

Fiqure 2. Model and Replica Chart (From Klein, B.:

Language, Speech, and Hearing Services in Schools, 15, p. $270)$. 
with phonological processes.

Shriberg and Kwiatkowski (1980) also developed a procedure which was time-saving when compared to their earlier procedures. In their procedure, they suggest analyzing a 200-225 word language sample in order to obtain 90 intelligible words to be analyzed for eight naturally occurring processes. Appropriate forms and worksheets are included in the monograph to aid in the analysis. The procedure and worksheets help save time compared to an analysis of a language sample which would analyze many more processes. When seven students were timed in transcribing and analyzing the same tape, the range of time needed to complete the entire procedure was 1 hour, 30 minutes to 3 hours, 30 minutes (Shriberg \& Kwiatkowski, 1980). This would be an unacceptable time allotment for the public school speech-language pathologist. It could be expected that the time to complete the procedure would decrease as the clinician became more familiar with the process. They further reported that experienced clinicians complete the procedure within approximately 1 hour, 40 minutes which still appears to be fairly lengthy.

There have been other computer programs besides the CAPP developed to help the clinician save time, such as the Programs to Examine Phonetic and Phonologic Evaluation

Records (PEPPER) (Shriberg, 1986). 


\section{VALIDITY AND RELIABILITY OF THE APP AND THE KLPA}

The advantages of a phonological process analysis of a continuous speech sample over one-word elicited response analysis have been documented (Shriberg \& Kwiatkowski, 1980). The validity, however, of one-word phonological assessment has been shown through several studies which compared one-word response tests (e.g., the APP and KLPA) to analysis of spontaneous speech samples. Most of the researchers found that one-word response analyses of phonological processes can be just as effective in determining initial phonological remediation targets as a spontaneous speech sample, but most of them indicated that in order to obtain a thorough phonological analysis, a spontaneous language sample should also be analyzed (Andrews \& Fey, 1986; Benjamin \& Greenwood, 1983; Dyson \& Roblnson, 1987; Klein, 1984; Paden \& Moss, 1985). Conversely, others have stressed that a more efficient means (such as one-word response tests) of assessing phonologically-impaired children is needed in order to be practical in time-constralned situations (Klein, 1984; Garn-Nunn, 1986).

Vailidity of the APP

Although the APP is not standardized, many phonological process specialists who have studied it consider it to be a reliable means of evaluating 
phonological processes in disordered children (Andrews \& Fey, 1986; Benjamin \& Greenwood, 1983; Dyson \& Robinson, 1987; Paden \& Moss, 1985).

Andrews and Fey (1986) completed a study which compared the spontaneous words from the APP to words obtained in a spontaneous speech sample and found the sampling condition made no difference in the severity level determined for each child. They did not compare each individual process to determine if they were significantly different.

Benjamin and Greenwood (1983) compared procedures of the APP, PPACL (modified), and the phonological Process Protocol (Khan Lewis, 1982), which is an experimental version of the KLPA. They determined the percent of occurrence for five different phonological processes strongly correlated among the three tests.

Paden and Moss (1985) compared the NPA, the APP, and the PPACL. They reported that "essentially similar" processes were identified when comparing all three procedures. Original plans for this study were to involve eight children with severely disordered phonology, but due to unintelligibility and thus inability of the clinician to transcribe a spontaneous speech sample, only three children were analyzed. They further suggested, if a child is severely unintelligible, a one-word response format may be the most realistic way to obtain an assessment. 
Dyson and Robinson (1987) also found similar results when comparing the NPA, APP, and the PPACL. Generally they found that the initial remediation targets were the same regardless of which assessment procedure was used.

Although the APP has not been standardized at this time, procedures have been undertaken to begin obtaining data for its standardization (Griffith, 1987). Overall the literature indicates the APP and/or a one-word phonological analysis is just as effective in determining initial phonological remediation targets as a spontaneous speech sample. It also indicates the APP is one of the quicker tests used to determine these targets.

This researcher has not found any studies which dealt with the issue of whether the CAPP results are significantly different from manual analysis; however, the developers of the CAPP meant for it to be used strictly as a supplement to a thorough manual analysis. Since the APP is one of the quicker phonological assessments and the use of the CAPP has been shown to decrease the analysis time tremendously (Hodson, 1985), then it is possible that the time it takes to complete this procedure will be shorter or will not be significantly different than the time it takes to complete the GFTA and/or the PAT.

Reliability and Validity of the KLPA

The KLPA is another widely used phonological process assessment tool. It was designed to analyze 
phonologically the responses obtained from the soundsin-Words subtest of the GFTA (a phonetic analysis). This assessment tool makes it possible for the clinician to administer only one test and obtain both a phonetic, as well as a phonologic analysis. In other words, if clinicians test children for phonetic errors by using the GFTA and then realize the children need a phonologic assessment, the clinicians do not need to re-test the children, but can analyze the same responses by using the KLPA. Additionally, if the clinicians only want a phonological analysis and do not want to complete a phonetic analysis, they can simply administer the sounds-in-words subtest of the GFTA and analyze this subtest with the KLPA analysis form.

The KLPA is a standardized assessment tool. A total of 852 children reflecting $U$. S. population in sex, geography, and ethnic affiliation between the ages of 2-0 and 5-11 were used to develop normative data. This occurred in 7 states and 41 sites.

\section{Reliability of the KLPA. Khan and Lewis (1986)} reported three types of reliability for the KLPA. They include short-term test re-test, long-term test-retest, and interrater. The average short-term rellability coefficient was very high for both the speech simplification rating (.90) and the composite score (.96).

The long term reliability of the KLPA was completed 
by retesting 51 children one year after the initial standardization. "The standardized difference (average difference divided by standard deviation) is . 31 for the speech simplification rating and .85 for the composite score" (Khan \& Lewis, 1986, p. 32). However, the authors stress that these "two variables cannot be directly compared" because the speech simplification rating is an "age-referenced normative variable," and thus the composite score would have a greater change (over a year) than the speech simplification rating.

In order to determine the interrater reliabilty, 30 children were evaluated by 2 different raters. This revealed a very high coefficient for both the speech simplification rating (.97) and the composite score (.97).

Validity of the KLPA. Construct validity and content validity were both reported on the KLPA (Khan \& Lewis, 1986). The construct validity was supported by developmental changes, profiles of scores for children with speech disorders, interrelationships among the phonological processes, internal consistency of the test, and correlations with articulation tests. The authors reported, "The decrease of mean raw scores from one age to the next provides ample support for the construct that individual and overall process usage is age related" (p. 34).

Content validity was provided by the large number of 
opportunities for phonological processes to be produced in the consonants contained in the target words. The KLPA provides between 6 and 44 opportunities to produce each of the 15 KLPA phonological processes.

The KLPA appears to be a reliable and valid phonological assessment tool. Bernthal and Bankson (1988) stated "(KLPA) test data reported in the manual are probably the most complete data available on children's use of phonological processes based on a closed set of stimulus words" (p. 239).

\section{SUMMARY}

A number of phonetic, as well as phonologic, assessment approaches exist. The differences between the two main types of assessments have been documented, as well as the need to treat specific children individually according to their phonetic, phonologic, or mixed disorder. Although phonetic approaches appear to be quicker to administer and analyze, this may not be the most effective way to treat the children, especially if they have phonologic errors and not phonetic errors. Even though some phonological process assessments are quite time-consuming to administer, others are less lengthy. Since time constraint is one of the more frequent complaints of public school speech-language pathologists when referring to phonological process assessments, this 
study was completed in order to determine if a less time-consuming, as well as possibly more effective approach, for assessing phonological processes was available. 
CHAPTER I I I

METHODS AND PROCEDURES

METHODS

\section{Subjects}

Twelve children were selected from a pool of potential subjects from clinical files at the Portland state University (PSU) speech and Hearing Clinic and from speech-language pathology referrals. Only those with signed parental release forms were considered for inclusion in the study (see Appendix $C$ ). The 12 subjects ranged from 4-1 to 6-7 years of age. In addition, all subjects selected met the following criteria:

1. hearing within normal limits in one ear based on an audiometric screening test, given within one week of the study, for the frequencies of $500,1000,2000$, and 4000 $\mathrm{Hz}$ at $25 \mathrm{~dB}$ HL (re: ANSI 1969);

2. ability to be conditioned to each test given, which was judged subjectively by the examiner giving the test;

3. no known organic disorder or structural deficit which might contribute to a speech sound disorder based on information in the child's clinic file and/or parent report; 
4. diagnosed with a mild, moderate, or severe articulation/phonology disorder based on information obtained from the testing for this study.

\section{Examiners}

Five speech-language pathology students enrolled in the PSU Speech and Hearing Sclences Program were selected as examiners for this study. They met the following criteria:

1. had given each speech sound disorder test used in this study at least one time and no more than five times,

2. had completed at least two PSU speech and Hearing sciences clinics prior to participating in this study.

Before participating in this study, the examiners completed a questionnaire regarding their experiences with the administration of each test used in this experiment (Appendix D). They also completed a 30-minute training session which included a review of the administration, analysis, and timing procedures for the experimental tests (Appendices $\mathrm{E} \& \mathrm{~F}$ ).

\section{Measurement Instruments}

The hearing screening instrument used in this investigation was the Beltone Portable Audiometer. It is a wide range audiometer that utilizes the frequency range of 
125-8000 Hz. A TDK super dynamic 90-minute audio cassette tape was used to record the subjects' responses. A Panasonic audio tape recorder was used to record the responses and an Advance digital quartz stop watch was used to time the administration and analysis of the tests.

\section{Experimental Tests}

The experimental tests used in this study included the APP, CAPP, GFTA, KLPA, and PAT.

APP. The APP is designed to assess the usage of selected phonological processes. The words are spontaneously produced by the children as they choose and name three-dimensional objects which are set before them. The transcribed utterances are examined to identify deviations between the testees' productions and the adult target forms. These errors are described according to the type of phonological process deviation exhibited. The complete test elicits 50 words and analyzes 35 processes (Appendix G).

CAPP. The CAPP (Hodson, 1985) is a computer program which is designed to evaluate the responses obtained from the APP. The computer program formulates a phonological analysis summary which includes pattern deviations, the percentage of occurrence of each pattern, the average of phonological processes used by the testee, a phonological deviancy score, a severity interval, and a list of 
suggested phonological processes to use in remediation. (Appendix $H$ shows a sample of a completed CAPP analysis.) Phonological process deviations analyzed by the CAPP include syllable reduction, prevocalic singleton omission, postvocalic singleton omission, consonant sequence reduction, strident deviation, velar deviation, liquid (1) and liquid $(x)$ deviations, nasal deviation, and glide deviation (Appendix A).

GFTA. The GFTA is composed of three subtests, including the sounds-in-Words subtest, the stimulability subtest, and the sounds-in-sentences subtest. The Sounds-in-Words subtest is designed to assess an individual's production of consonant sounds in initial, medial, and final positions in words. The words in this subtest are elicited by instructing the child to name the presented pictures. The stimulability subtest assesses the stimulability of each misarticulated phoneme in syllables, words, and sentences. The Sounds-in-Sentences subtest assesses speech sound production in a spontaneous manner. The words are elicited by reading two stories to the child and then instructing the child to re-tell the story by using the pictures as memory aids. The test consists of 44 colored pictures on easel presentation, two picture stories to elicit words in context, a manual, and a response form.

KLPA. The KLPA is designed to supplement the diagnostic information given in the GFTA. The 44 words 
elicited by the GFTA on the sounds-in-Words subtest are transcribed onto the KLPA analysis sheet where the responses are analyzed for the use of 15 phonological processes (Appendix B). Of these 15 processes, 12 are characteristic of normal speech development. They include: deletion of final consonants, initial voicing, syllable reduction, palatal fronting, deaffrication, velar fronting, consonant harmony, stridency deletion, stopping of fricatives and affricates, cluster simplification, final devolcing, and liquid simplification. Of the 15 processes, 3 are nondevelopmental, including: deletion of initial consonants, glottal replacement, and backing to velars.

PAT. The PAT consists of 72 colored photographs. The test is designed to evaluate the production of consonants, vowels, and dipthongs. The last 3 pictures test connected speech. The child is instructed to name the picture to which the examiner points.

The speech sound disorder tests mentioned above were chosen for this experiment because the GFTA and the PAT are widely used by speech-language pathologists, the KLPA is used in association with the GFTA, and the APP/CAPP appears to be the fastest method of obtaining a phonological assessement. 
PROCEDURES

Setting

All screening and testing was conducted in quiet, well-lit rooms in the PSU speech and Hearing clinic. The subjects were examined one at a time. Each child was given a 5-minute break after each test had been administered and/or between subtests if the child was showing signs of restlessness.

\section{Screening Procedures}

The subjects' files were screened to determine their appropriateness for this study. The screening began with review of clinical records and/or interview with the speech-language pathologist famillar with the child. This was completed to determine if the child had been diagnosed or was suspected to have a phonological/articulation disorder. If the subject met this qualification, a puretone hearing screening test was completed to determine normal hearing levels. The children who passed the screening were considered as potential subjects.

Potentlal subjects who were not diagnosed as having a mild, moderate, or severe phonological/articulation disorder, and/or unable to condition to any one of the tests given, were not selected as subjects for this study.

\section{Examiner's Procedures}

The APP, the GFTA, and the PAT were administered to 
the subjects in one session by the examiners. Four examiners each tested two children and one examiner tested four children.

The procedures for administering and scoring the PAT, the GFTA, and the KLPA were followed as instructed in their respective manuals. The APP was administered as instructed in the manual and analyzed by using the CAPP as instructed in the CAPP manual.

The order of test administration was varied (see Table I). This procedure was followed to help counterbalance factors such as child fatigue and/or child-clinician familiarity which could have affected the time needed to administer the tests.

\section{Timing Procedures}

Each clinician timed the administration of each test separately. The timing began when the clinician and child were in their seats and immediately prior to the clinician giving the instructions to the child. The time it took to set up the materials was not included. The timing stopped immediatley after the clinician administered the last test item to the child. In order to obtain an administration time of the KLPA, the examiner separately recorded the time it took to administer the sounds-in-Words subtest of the GFTA. Each examiner was given written instructions on the timing procedures to be used (Appendix F). In addition to 
TABLE I

ORDER OF THREE TESTS ADMINISTERED

Tests

\begin{tabular}{|c|c|c|c|c|}
\hline $\begin{array}{l}\text { Exam iner } \\
\text { Number }\end{array}$ & $\begin{array}{l}\text { Subject } \\
\text { Number }\end{array}$ & $\begin{array}{c}\text { Goldman-Fristoe } \\
\text { Test } \\
\text { of } \\
\text { Articulation }\end{array}$ & $\begin{array}{l}\text { Photo } \\
\text { Artic- } \\
\text { ulation } \\
\text { Test }\end{array}$ & $\begin{array}{c}\text { Assessment } \\
\text { of } \\
\text { Phonological } \\
\text { Processes }\end{array}$ \\
\hline \multirow{4}{*}{1} & 1 & first & second & third \\
\hline & 2 & third & first & second \\
\hline & 3 & second & third & first \\
\hline & 4 & first & second & third \\
\hline \multirow{2}{*}{2} & 5 & third & first & second \\
\hline & 6 & second & third & first \\
\hline \multirow{2}{*}{3} & 7 & first & second & third \\
\hline & 8 & third & first & second \\
\hline \multirow{2}{*}{4} & 9 & second & third & first \\
\hline & 10 & first & second & third \\
\hline \multirow{2}{*}{5} & 11 & third & first & second \\
\hline & 12 & second & third & first \\
\hline
\end{tabular}


the examiners' timing their own administration of the test, this researcher timed each clinicians' first subject tested to insure accurate timing procedures. Each session was also tape-recorded to allow re-timing of the tests if errors were made in the timing procedures during the testing.

The analysis of each test was timed individually by each clinician. Each examiner was observed during the analysis of their first subject's results, by this researcher, in order to insure that each examiner was following the correct timing procedures. The test results were analyzed within 6 weeks from the time of the administration of the tests. The analysis of the KLPA, PAT, and GFTA was completed in a well-lit, quiet room. The analysis of the APP was completed in the PSU Computer Lab. The timing of the analysis of each test began when the clinician had assembled all materials needed to analyze the tests. The timing of each test was completed when the clinician was satisfied that all results had been calculated. Each clinician was given a form to record the times they had obtained (Appendix I).

\section{DATA MEASUREMENT AND ANALYSIS}

The administration time and the analysis time for each test was individually recorded. The completion time of each testing procedure was calculated from which means, 
standard deviations, and ranges were determined for each speech sound test studied. In order to determine if the mean completion times of each of the phonologic tests (APP/CAPP and/or KLPA) was significantly different than the mean completion times for each of the phonetic tests (PAT and the GFTA), a two-tailed t-test for dependent means was calculated. Additionally mean completion times of the APP and the KLPA were compared by a two-tailed t-test for dependent means. An alpha level of .05 was set for determining statistical significance. For ancillary information, the mean completion times for each severity level (mild, moderate, and severe) was calculated to determine if the child's severity level influenced the amount of time needed to complete the test. 
CHAPTER IV

\section{RESULTS AND DISCUSSION}

\section{RESULTS}

The stated purpose of this study was to determine if the time it takes to administer and analyze a phonological test is significantly different than the time it takes to administer and analyze a phonetic test. specifically, the APP/CAPP and the KLPA were compared with the PAT and the GFTA .

The first question posed was: Is the time it takes to administer and analyze phonological assessments, i.e., APP and KLPA significantly different than the administration and analysis time of phonetic tests, 1.e., PAT and GFTA? The answer to this question varies depending on the tests being compared. Appendix $J$ presents the raw data and Table II shows the means, standard deviations, and ranges of time for each test, in addition to t-test comparisons of the administration and analysis times of the phonological versus phonetic tests. All t-test comparisons of phonological versus phonetic tests revealed a significant difference beyond the .05 level of confidence. The $\operatorname{APP} / \operatorname{CAPP}(\bar{x}=22: 56 ; \mathrm{SD}=3: 29)$ took significantly less time to adminster and analyze than the GFTA $(\bar{x}=26: 13$; 
TABLE II

MEANS, STANDARD DEVIATIONS, RANGES, AND $t$-TEST COMPARISONS FOR PHONOLOGIC VERSUS PHONETIC

COMPLETION TIMES

TEST

TIME (minutes: seconds)

\begin{tabular}{|c|c|c|c|c|}
\hline COMPARI SONS & MEAN & S.D. & RANGES & $t$-values \\
\hline $\begin{array}{l}\text { APP / CAPP } \\
\text { PAT }\end{array}$ & $\begin{array}{l}22: 56 \\
11: 27\end{array}$ & $\begin{array}{l}3: 29 \\
2: 04\end{array}$ & $\begin{array}{l}17: 20 \text { to } 27: 35 \\
7: 48 \text { to } 15: 36\end{array}$ & $\begin{array}{l}9.943 * \star \\
(d f=11)\end{array}$ \\
\hline $\begin{array}{l}\text { APP/CAPP } \\
\text { GETA }\end{array}$ & $\begin{array}{l}22: 56 \\
26: 13\end{array}$ & $\begin{array}{l}3: 29 \\
4: 05\end{array}$ & $\begin{array}{l}17: 20 \text { to } 27: 35 \\
18: 35 \text { to } 32: 21\end{array}$ & $\begin{array}{l}-2.206 * \\
(\mathrm{~d} E=11)\end{array}$ \\
\hline $\begin{array}{l}\text { KLPA (without } \\
\text { transcription) } \\
\text { PAT }\end{array}$ & $\begin{array}{l}37: 26 \\
11: 27\end{array}$ & $\begin{array}{l}11: 01 \\
2: 04\end{array}$ & $\begin{array}{l}22: 11 \text { to } 53: 01 \\
7: 48 \text { to } 15: 36\end{array}$ & $\begin{array}{l}8.826 * \pi \\
(\mathrm{df}=11)\end{array}$ \\
\hline $\begin{array}{l}\text { KLPA (without } \\
\text { transcription) } \\
\text { GFTA }\end{array}$ & $\begin{array}{l}37: 26 \\
26: 13\end{array}$ & $\begin{array}{l}11: 01 \\
4: 05\end{array}$ & $\begin{array}{l}22: 11 \text { to } 53: 01 \\
18: 35 \text { to } 32: 21\end{array}$ & $\begin{array}{l}4.424 * \pi \\
(d f=11)\end{array}$ \\
\hline $\begin{array}{l}\text { KLPA (with } \\
\text { transcription) } \\
\text { PAT }\end{array}$ & $11: 27$ & $11: 56$ & $\begin{array}{l}25: 24 \text { to } 60: 41 \\
7: 48 \text { to } 15: 36\end{array}$ & $\begin{array}{l}9.953 * * \\
(d f=11)\end{array}$ \\
\hline $\begin{array}{l}\text { KLPA (with } \\
\text { transcription) } \\
\text { GFTA }\end{array}$ & $\begin{array}{l}43: 14 \\
26: 13\end{array}$ & $\begin{array}{l}11: 56 \\
4: 05\end{array}$ & $\begin{array}{l}25: 24 \text { to } 60: 41 \\
18: 35 \text { to } 32: 21\end{array}$ & $\begin{array}{l}6.169 * \star \\
(\mathrm{df}=11)\end{array}$ \\
\hline
\end{tabular}

* slgnificant beyond .05 level of confidence

** significant beyond.001 level of confldence 
$S D=4: 05)$ and the APP/CAPP took significantly more time than the $\operatorname{PAT}(\bar{x}=11: 27 ; S D=2: 04)$.

The timing of the KLPA was recorded in two different ways because the KLPA results can be transcribed from the GFTA Sounds-in-Words subtest (KLPA with transcription) or it can be administered soley and the results written directly onto the KLPA response form (KLPA without transcription). The KLPA with transcription $(\bar{x}=43: 14 ;$ SD $=11: 56)$ took significantly more time than the GFTA and the PAT. The administration and analysis time of the KLPA without transcription $(\bar{x}=37: 26 ; S D=11: 01)$ also took significantly more time than both the GFTA and the PAT. The corollary question asked was: Is the time it takes to complete the APP/CAPP significantly different than the completion time of the KLPA? The results from this study indicated it took much less time to complete APP/CAPP than both the KLPA with transcription and the KLPA without the transcription time added (Table III).

\section{DISCUSSION}

This investigator sought to determine if the perception of clinicians regarding the extra time needed to assess phonologically-impaired children was accurate. The data from this study revealed that the APP/CAPP, a phonologic test, is more time-efficient than the GFTA, a phonetic test (Table II). In the other comparisons, the 
TABLE III

MEANS, STANDARD DEVIATIONS, RANGES, AND $t$-TEST COMPARISONS FOR THE APP/CAPP VERSUS THE KLPA

COMPLETION TIMES

TEST

TIME (minutes: seconds)

\begin{tabular}{|c|c|c|c|c|}
\hline COMPAR I SONS & MEAN & S.D. & RANGES & $t$-values \\
\hline & $22: 56$ & $3: 29$ & $17: 20$ to $27: 35$ & $-4.38 \star \star$ \\
\hline $\begin{array}{l}\text { KLPA (without } \\
\text { transcription) }\end{array}$ & $37: 26$ & $11: 01$ & $22: 11$ to $53: 01$ & $(d f=11)$ \\
\hline $\mathrm{APP} / \mathrm{CAPP}$ & $22: 56$ & $3: 29$ & $17: 20$ to $27: 35$ & \\
\hline $\begin{array}{l}\text { KLPA (with } \\
\text { transcription) }\end{array}$ & $43: 14$ & $11: 56$ & $25: 24$ to $60: 41$ & $\begin{array}{l}-5.688 * * * \\
(a f=11)\end{array}$ \\
\hline
\end{tabular}

** significant beyond .01 level of confldence

$* * *$ signiflcant beyond .001 level of confidence

phonologic tests required more time to complete than the phonetic tests.

Additional information obtained from the results of this study indicated the length of time it takes to complete a phonologic or phonetic test increases as the severity level of the child's speech sound disorder increases. This observation can be seen in Figure 3 .

Advantages and Disadvantages of Assessment Tools

Depending on a client's severity level, and/or the clinician's theoretical background, the clinician might want to administer a phonetic analysis, a phonologic analysis, or both. The amount of time it takes to 


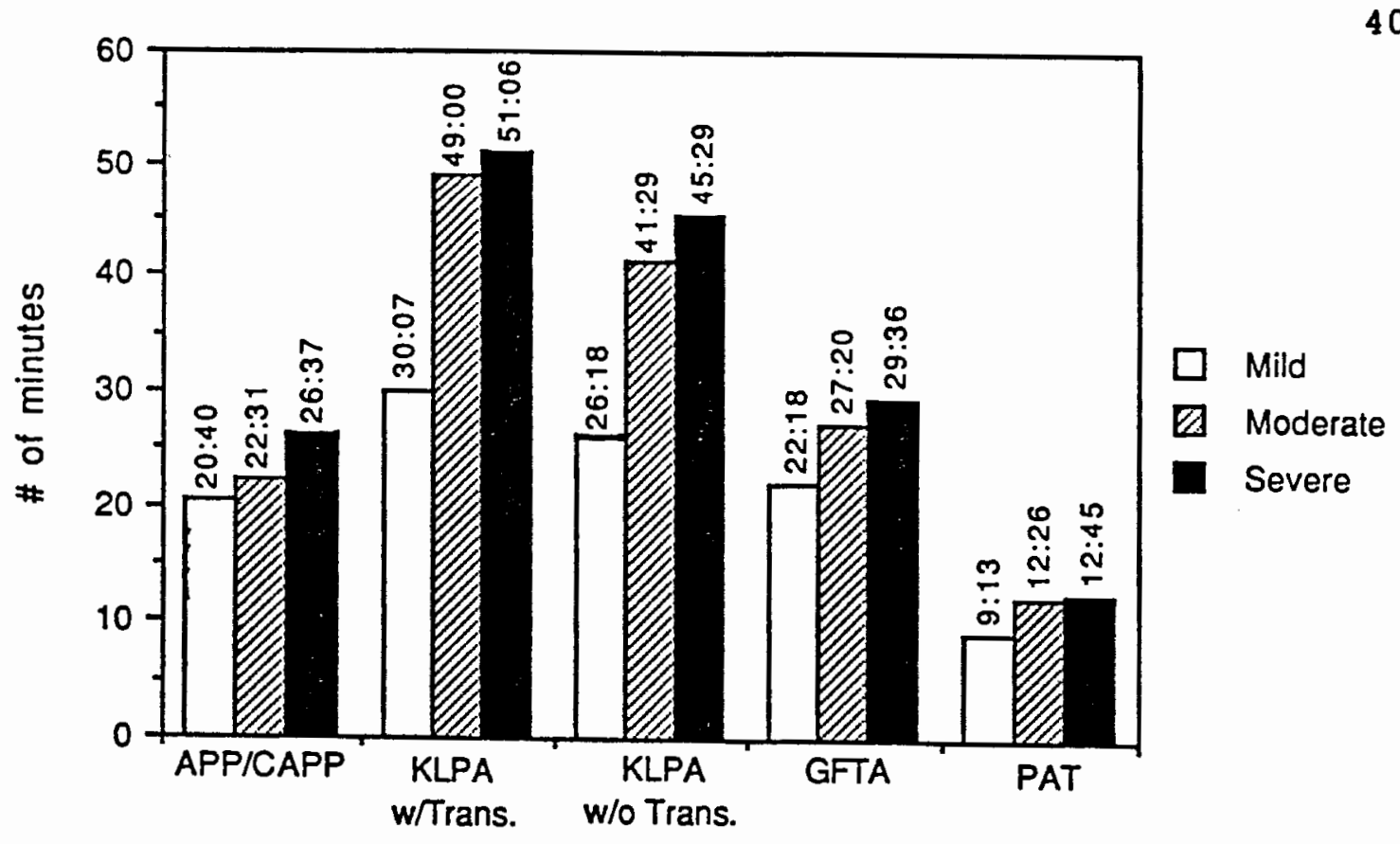

Figure 3. Mean Completion Times According to the Child's Severity Level.

administer and analyze a test generally plays a large part in the busy clinician's decision of which test/tests to administer. Other attributes which also are considered when deciding which test to administer include amount of information obtained from analyzing the test, initial cost, maintenance cost, reliability, validity, and availability and/or convenience of the test. By examining these attributes in conjunction with time efficiency of each test, clinicians can choose the most efficient and/or suitable test for their needs. Table IV lists each of these qualities and rates them positively or negatively for each individual test used in this study. These attributes as related to the four tests in this study will be explained further. 
TABLE IV

POSITIVE AND NEGATIVE ATTRIBUTES OF TESTS

Phonologic Tests

Attributes

CAPP / APP KLPA

Phonetic Tests

GFTA

PAT

Time

Efficiency

$+$

$+$

$+$

Amount of

Information

obtained

Initial

Cost

$+\quad+$

$+$

-

Maintenance

Cost

$+$

- +

$+$

Reliability

- +

$+$

$+$

$+$

Validity

$+$

$+$

$+$

$+$

Availability/

Convenience

$-$

$+$

$+$ 
Time Efficiency. According to the results of this study, the PAT, a phonetic test, would be the test of choice if the examiner were choosing a phonetic/phonologic test soley based on time efficiency. Pendergast et al. (1969) stated the PAT takes less than 5 minutes to complete. The results from this study found the mean time to complete the PAT was 11:27 with a range of $7: 48$ to $15: 36$ (Table II). The time it takes to complete the PAT is minimal compared to other tests and therefore this attribute receives a positive rating.

The APP/CAPP, a phonologic assessment tool, was the second most time-efficient test used in this study $(\bar{x}=$ $22: 56)$. Hodson $(1985,1986)$ reported the APP/CAPP takes from 25 to 30 minutes to complete. In the present study the time obtained for the lower range (17:20) and the time obtained for the higher range (27:35) was slightly less than the higher and lower ranges reported by Hodson (1985, 1986). Since this was found to be one of the least time-consuming tests in this study, it receives a positive rating in this category.

Goldman and Fristoe (1986) did not report the administration or analysis times of the GFTA, a phonetic test. Weiss et al. (1987) reported that the adminstration time is approximately 20 minutes and Bernthal and Bankson (1988) stated it takes 10 to 12 minutes to administer. Neither author gave an estimation of the analysis time nor 
conditions of the timing. This study found that it took a range of $15: 49$ to $24: 27$ to administer the GFTA, which is similar to the time suggested by Weiss et al. (1987), but is slightly longer than the time suggested by Bernthal and Bankson (1988). In this study the mean completion time of the GFTA was $26: 13$ with a range of $18: 35$ to $32: 21$. Although this amount of time is longer than the time it took to complete the PAT and the APP/CAPP, this author judges that this is still a reasonable allotment of time needed to complete a thorough speech sound analysis, so the GFTA receives a positive rating for this attribute.

According to Khan and Lewis (1986), it takes 15 to 40 minutes "to complete" the KLPA, a phonologic test, although they do not describe any of the conditions present in obtaining this time estimate. The times obtained in this study were longer than those described in the KLPA manual. The KLPA without transcription took a mean time of $37: 26$ with a range time of 22:11 to 53:01, while the KLPA with transcription took a mean time of $43: 14$ with a range of $25: 24$ to $60: 41$. Since these times are considerably longer than the other three tests and might be slightly unreasonable for a busy clinician, a negative rating is given to the KLPA in this category.

Amount of Information obtained. An examiner possibly obtains more information from the KLPA, a phonologic test, than from any of the other tests discussed. Scoring the 
KLPA yields a composite score, percentile rank, a speech simplification rating, and an age equivalent score. The goal selection worksheet yields a phonological remediation guide, which gives suggestions on which processes to target and a phonetic inventory, which allows the clinician to see whether the client's phonetic repertoire is limited in some way (Khan \& Lewis, 1986). The KLPA receives a positive rating in this category.

Information obtained from completing the APP/CAPP, a phonologic assessment tool, includes percentage of occurrence of ten phonologic process pattern deviations, the phonological deviancy score, the severity level, and patterns which should be targeted for remediation (Appendix E). If the examiner needed information on additional processes, a manual analysis of the APP, which assesses 30 processes, could be completed. Although a manual analys is of the APP yields information on 20 more processes, it will take the examiner much longer to analyze. The APP/CAPP yields a large amount of pertinent information needed to begin remediation and therefore it receives a positive rating in this category.

scoring the GFTA, a phonetic test, yields percentile ranks for the word level and for syllable stimulability. This test allows the examiner to assess production of sounds in the initial, medial, and final positions for imitated syllables, spontaneous words, and spontaneous 
sentences. Additionally, the responses from the Sounds-in-words subtest can be analyzed phonologically on a KLPA response form. The GFTA is rated positive for this attribute.

Even though the PAT, a phonetic test, is the best choice for time efficiency, the amount of information obtained appears to be the least of all tests studied. Although this test includes transparent age-appropriate overlays which allow the examiner to compare visually "the subject's articulation errors with norms," the only score provided is that obtained by counting the number of errors (Pendergast et al., 1969). Compared to the other tests used, the PAT yielded minimal information and therefore receives a negative rating in this category.

Initial cost. The cost of the PAT is $\$ 44.95$ for the test booklet and 96 additional recording sheets (Interstate Printers \& Publishers (IPP), (1989). It is the least expensive test in this study and receives a positive rating for initial cost.

The cost of the KLPA $k$ it is $\$ 42.50$, which includes a manual, 25 analysis forms, and a folder (American Guldance Service (AGS), 1989). However, in order to administer the KLPA, the examiner must also have the GFTA easel booklet which contains pictures to elicit the child's responses. This booklet is $\$ 62$ (AGS, 1989). The total initial cost of the KLPA is over $\$ 100$ and over twice as much as the PAT; 
therefore, the KLPA receives a negative rating in this category.

According to the AGS (1989) the cost of the entire GFTA kit is $\$ 75$, which includes an easel-type test, a manual, and 25 response forms. This cost appears to be fairly expensive compared to the PAT and therefore receives a negative rating in this category.

The initial cost for the APP, as used in this study, is $\$ 19.95$ for 48 recording forms (Appendix D) and a manual. The test also requires three-dimensional objects/toys which are not provided in the kit. If the clinician is resourceful, the objects can cost as little as a few dollars. Although the initial cost of the APP is relatively minimal, the CAPP program, which is compatible with Apple computers (and in 1989 , IMB computers) is $\$ 85$. Since the initial cost for the APP/CAPP is greater than $\$ 100$ and more expensive than the other tools mentioned, a negative rating is given.

Maintenance cost. Once the clinician has invested in the initial cost of the APP/CAPP, GFTA, or the PAT, mantenance costs are very minimal. The only additional costs would probably be the purchase of more recording forms. They cost $\$ 5$ for 48 forms, $\$ 9.50$ for 28 forms, and $\$ 5$ for 96 forms, respectively. All three of these tests receive a positive rating in this category. 
The maintenance cost of the KLPA is the most expensive of the four assessment tools studied. The analysis forms are color-coded and very detailed and cost $\$ 28.75$ for 28 forms. The KLPA receives a negative rating in this category.

Reliability / Validity. Bernthal and Bankson (1988) stated "The test data reported in the (KLPA) manual are probably the most complete data available on children's use of phonological processes based on a closed set of stimulus words" (p. 239). (See Chapter II for more information on the reliability and validity of the KLPA.) Both of these categories receive a positive rating due to the thorough research data provided by Khan and Lewis (1986).

Goldman and Fristoe (1986) reported test-retest, inter-rater, and intra-rater reliability. The range of the test-retest reliability for the 3 subtests was very high $(.91$ to .95$)$. For the sounds-in-words subtest the inter-rater reliability (.92) and the intra-rater reliability (.91) was also very high. The validity of the GFTA was shown by using content validity. Both categories receive a positive rating.

Pendergast et al. (1969) reported test-retest reliability for the PAT as very high (.99). They reported criterion-related validity by comparing it to the Bryngelson-Glaspey and the Templin-Darley, with correlations of .974 (very high) and.815 (high), 
respectively. The number of different types of reliability and validity reported on the PAT is limited compared to the GFTA and the KLPA, but the validity and the reliability is reported to be high to very high and thus both attributes receive a positive rating.

As mentioned earlier in chapter II, the APP/CAPP, is not standardized (although present standardization is underway). The test has been found to be valid (see Chapter II) and thus this category receives a positive rating. It has not been reported to be reliable therefore this category receives a negative rating.

Availability/Convenience. The KLPA and GFTA can be readily obtained from AGS (1989). Their manuals and tests can be easily transported from site to site due to their relatively small size. This attribute of the KLPA and GFTA recieves a positive rating.

The PAT can be easily ordered through IPP (1989). The test consists of 72 colored photographs with 9 pictures on each page and a manual which are both conveniently contained in a spiral-type book which can be transported easily. Due to the above-mentioned characteristics, this attribute of the PAT is rated as positive.

The APP/CAPP can readily be ordered through IPP (1989), but collecting the 3-dimensional objects can be inconvenient and carrying them from site to site can be awkward. Additionally, the need to use a computer to 
analyze the data may be inconvenient. The APP/CAPP receives a negative rating in this category.

\section{Concluding Remarks}

Although time efficiency is an important test attribute in the busy clinician's decision of which speech sound assesment tool to administer, there are also additional factors to incorporate into the choice. If the clinician chooses a test soley based upon time efficiency, then the PAT would be the test of choice for a phonetic assessment, but it appears to yleld the least amount of information. Although the APP/CAPP is the most timeefficlent phonologic test and it additionally yields a large amount of information, it is not standardized. Both of these tests, as well as other tests, have undesirable characteristics as well as desirable characteristics (Table IV). When choosing an assessment test, all of the attributes need to be considered in order to obtain the most efficient and effective assessment tool from which the clinician can implement efficient and effective remediation. 


\section{CHAPTER V}

\section{SUMMARY AND IMPLICATIONS}

\section{SUMMARY}

In the past, many public school speech-language pathologists have verbalized that phonological process assessments are too time-consuming for those who are overly burdened with large caseloads. If a phonological assessment tool can be shown to take approximately the same amount of time as a typical phonetic analysis, then perhaps public school speech-language pathologists would analyze and treat their phonologically-impaired clients using a more appropriate phonological approach instead of a less effective phonetic approach. The main postulation of using a phonological process-based approach is that remediation time is saved because generalization occurs across the entire process when only a few sound errors are treated.

In reviewing the literature, statistical comparisons between the time it takes to complete (administer and analyze) a phonological analysis and the time it takes to complete a phonetic analysis were not found. This lack of data lead to the development of this study, which was undertaken in order to determine the accuracy of the 
clinician's perceptions that a phonologic process assessment is more time-consuming than a phonetic assessment. The phonologic process tests used in this study were the Assessment of Phonological Processes-Revised (APP) (Hodson, 1986) which was analyzed by the Computer Analysis of Phonological Processes (CAPP) (Hodson, 1985) and the Khan-Lewis Phonological Analysis (KLPA) (Khan \& Lewis, 1986). The phonetic tests used in this study were the Goldman Fristoe Test of Articulation (GFTA) (Goldman \& Fristoe, 1986) and the photo Articulation Test (PAT) (Pendergast, Dickey, Selmar, \& Soder, 1969)

The purpose of this study was to determine if the time it takes to complete a phonological test was significantly different than the time it takes to complete a phonetic test. It was hoped this study would identify an instrument that the public school speech-language pathologist could use more effectively and efficiently to analyze phonologically-impaired children.

Twelve subjects, ages $4-1$ to $6-7$ years with mild, moderate, or severe phonologic and/or phonetic disorders participated in this study. Five speech-language pathology students who had experienced at least two speech and hearing clinics at PSU, were selected as examiners for this study.

The mean $(\bar{X})$ and standard deviation (S.D.) of the completion time of each test used in this study were 
calculated and are as follows: APP as analyzed by the APP (APP/CAPP): $\overline{\mathbf{x}}=22: 56$, S.D. $3: 29$; the KLPA with the transcription time from the GFTA Sound-in-Words subtest: $\bar{x}$ $=43: 14$, S.D. $=11: 56$; the KLPA without transcription time from the GFTA Sounds-in-Words subtest: $\bar{x}=37: 26$, S.D. $=$ 11:01; the GFTA: $x=26: 13$, S.D. $=4: 05$; the PAT: $\bar{x}=$ 11:27, S.D. = 2:04. Two-tailed t-tests for dependent means were used to compare two phonological tests (APP/CAPP and KLPA) with two phonetic tests (GFTA and PAT). The study revealed that each comparison was significantly different beyond the .05 level of confidence. The APP/CAPP (phonologic process test) takes significantly less time to complete than the GFTA (phonetic test). The PAT (phonetic test) takes significantly less time to complete than the APP/CAPP and the KLPA. The GFTA takes significantly less time to complete than the KLPA. Additionally, the phonological tests were compared with each other and the results revealed that the APP takes significantly less time to complete than the KLPA.

The data also revealed that the more severe the child's speech sound disorder, the more time is needed to complete a phonetic or phonologic test. Although the number of subjects that participated in this study is limited, information gathered might be helpful in demonstrating that there are phonologic tests, such as the 
$A P P / C A P P$, which are less time-consuming than some frequentiy used phonetic tests, such as the GFTA.

\section{IMPLICATIONS}

\section{Research}

Further research regarding the timing of phonologic process tests is warranted. A replication of this study could be conducted using more experienced clinicians instead of students and/or with a larger sample size, which would result in a more representative sample. This larger sample size could also be completed with children who are soley moderately and severely impaired. In addition, the same phonologic process tests, i.e., APP/CAPP or KLPA or different phonologic process tests, i.e., NPA or PPACL could be compared to the same phonetic tests, i.e., PAT or GFTA or different phonetic tests, 1.e., The Templin-Darley Tests of Articulation (Templin \& Darley, 1969) or The Arizona Articulation Proficiency Scale (Fudala, 1970).

Research comparing the timing of phonological process one-word elicited tests (APP/CAPP, KLPA or Compton-Hutton Phonoloqical Assessment, Compton \& Hutton, 1978 ) to phonological processes obtained from a language sample (NPA or Phonological Assessment of Child Speech, Grunwell, 1985) could be implemented to determine which has the greatest efficiency. 
Research which compares the times it takes to complete various computer-aided phonologic analysis versus the amount of time it takes to complete manual analysis of the same test might also be helpful. In addition, the time comparisons of various computer-aided phonologic analyses could be compared to each other, i.e., the CAPP versus the PEPPER. Further research in the development of computer programs for already exsisting phonologic assessment tools such as the KLPA could also be developed to help save the clinician time. Present computer programs such as the CAPP could be further developed in order to provide a more effective and thorough analysis, i.e., the CAPP program, which analyzes 10 processes, could be developed so it would calculate the 30 processes which are analyzed when completing a manual analysis of the APP.

A time comparison study of a phonological process remediation approach versus a phonetic remediation approach with phonologically-impaired children would also be very useful. If it could be empirically proven that a phonologic treatment approach saved significantly more time than a phonetic treatment approach then clinicians might be more apt to assess as well as treat phonologically-impaired children by using a more efficient as well as effective phonologic approach. 


\section{Clinical}

Results of the current study provide clinicians with additional information regarding which test is the most efficient to administer and analyze. According to the results of this study the APP/CAPP is the most efficient phonological processes test and the PAT is the most efficient phonetic test. Outcomes of this study will also help the clinician to know approximately how much time to allow when scheduling phonetic and/or phonologic assessments. It would also provide information on approximately how much additional time to allow if the child has a more severe impairment versus a mild impairment.

Data from this study could provide additional and/or more statistically accurate completion times for the authors to place in their manuals, since most of the times in the manuals appear to be estimations, which may be inaccurate.

In order for the clinician to be the most effective in treating and assessing the speech-impaired child, knowledge in phonetic assessments as vell as phonologic assessments are needed. This study gives the clinician some general knowledge on phonological processes which will help the clinican to be more effective. 


\section{REFERENCES}

American Guidance Service (1989). Circle Pines, MN.

Andrews N., \& Fey, M. E. (1986). Analysis of the speech of phonologically impaired children in two sampling conditions. Lanquage, Speech, and Hearing Services in Schools, 17, 187-198.

Benjamin, B. J., \& Greenwood, J. L. (1983). A comparison of three phonological assessment procedures. Journal of Childhood Communication Disorders, 7, 19-27.

Bernthal, J. E., \& Bankson, N. W. (1988). Articulation and phonological disorders. Englewood Cliffs, NJ: Prentice Hall.

Compton, A. J. (1976). Generative studies of children's phonological disorders: clinical ramifications. In D. M. Morehead \& A. D. Morehead (Eds), Normal and deficlent child language. Baltimore: University Park Press (PP. 61-96).

Compton, A. J., \& Hutton, S. (1978). Compton-Hutton phonological assessment. San Francisco: Carousel House.

Crary, M. A., \& Hunt, T. L. (1983), CV to CVC: A longitudinal report of a chlld with open syllables. Topics in Lanquage Disorders, 3, 35-44.

Dunn, C., \& Barron, C. (1982). A treatment program for disordered phonology: Phonetic and linguistic considerations. Language Speech, and Hearing Services in Schools, 13, 100-109.

Dyson, A. T., \& Robinson, T. W. (1987). The effect of phonological analysis procedure on the selection of potential remediation targets. Lanquage, Speech, and Hearing Services in Schools, 18, 364-377.

Edwards, M. L. (1983). Issues in phonological assessment. Seminars in Speech and Lanquaqe, $4,351-374$.

Elbert, M. (1983). A case study of phonological acquisition. Topics in Lanquage Disorders, $3,1-9$. 
Elbert, M., Dinnsen, D. A., \& Weismer, G. (1984). Phonological theory and the misarticulating child. Rockville, Maryland: American Speech-LanguageHearing Association.

Elbert, M. \& Gierut, J.A. (1986). Handbook of clinical phonology approaches to assessment and treatment.

San Diego, CA: College-Hill Press.

Fudala, J. (1970). Arizona articulation proficiency scale. Los Angelos: Western Psychological Services.

Garn-Nunn, G. (1986). Phonological processes and conventional articulation tests: considerations for analysis. Lanquage Speech and Hearing Services in Schools, 17, 244-252.

Goldman, R. \& Fristoe, M. (1986). Goldman-Fristoe test of articulation. Circle Pines, MN: American Guidance Press.

Griffith, L. J. (1987). Normative study of phonological process patterns of preschool children as measured by the Assessment of Phonological Processesrevised. Unpublished thesis, portland state University.

Grunwell, P. (1985). Phonological assessment of child speech. San Diego: College-Hill Press.

Hejna, R. (1963). Developmental articulation test. Ann Arbor, MI: speech Materials.

Hodson, B. W. (1986). Assessment of phonological processes-revised. Danville: Interstate Printers \& Publishers, Inc.

Hodson, B. W. (1985). Computer analysis of phonological processes. Stonington, IL. Phonocomp.

Hodson, B. W. (1983). A facilitative approach for remediation of a child's profoundly unintelligible phonological system. Topics in Lanquage Disorders, 3, 24-34.

Hodson, B. W. Paden, E. P. (1983). Targeting intelligible speech. San Diego, CA: College-Hill Press.

Ingram, D. (1981). Procedures for phonoloqical analysis of children's lanquage. Baltimore: University Park Press. 
The Interstate Printers \& Publishers, Inc. (1989). Danville, IL.

Khan, L. M. \& Lewis, N. (1982). Phonological process protocol. Field test edition.

Khan, L. M. \& Lewis, N. (1986). Khan-Lewis phonological analysis. Circle Pines, MN: American Guidance Service.

Klein, B. H. (1984). Procedure for maximizing phonological information from single-word responses. Lanquage, Speech, and Hearing Services in Schools, 15, 267-274.

Paden, E. P., \& Moss S. A. (1985). Comparison of three phonological analysis procedures. Language, Speech, and Hearing Services in Schools, 16, 103-109.

Paul, R. (1988). Lecture notes. Diagnosis and appraisal instructor. Portland state University.

Pendergast, K., Dickey, S. E., Selmar, J. W., \& Soder, A. L. (1969). Photo articulation test. Chicago: The King Company.

Schwartz, I. (1988). The use of phonological process analysis in the oregon public schools. From an article in the osHA Newsletter.

Schwartz, R. G. (1983). Diagnosis of speech sound disorders in children. In I. J. Meitus and B. Neinberg (Eds.), Diagnosis in speech-language pathology (pp. 113-149). Austin, Texas: Pro-ed.

Shriberg, L. D. $(1986)$. programs to examine phonetic and phonologic evaluation records. University of Wisconsin: Software Development and Distribution Center.

Shriberg, L. D., \& Kwiatkowski, J. (1980). Natural Process Analysis: A procedure for phonological analysis of continuous speech samples. New York: wiley.

Templin, M., \& Darley, F. (1969). The Templin-Darley tests of articulation. Iowa City: Bureau of Educational Research and Service, The University of I owa . 
Tyler, A. A., Edwards, M. L., \& Saxman, J. H. (1987). Clinical application of two phonologically based treatment procedures. Journal of speech and Hearing Disorders, 52, 393-409.

Weiner, F. (1979). Phonological process analysis. Baltimore: University Park Press.

Weiss, C. E., Gordon, M. E. Lillywhite, H. S. (1987). Clinical management of articulatory and phonologic disorders. Baltimore: Williams \&ilkins.

Vood, K. (1971). Terminology and nomenclature. In L. Travis (Ed.), Handbook of speech pathology and audiology. New York: Appleton-Century-Crofts. 


\section{APPENDIX A}

\section{PHONOLOGICAL PROCESSES DEFINITIONS USED IN THE}

ASSESSMENT OF PHONOLGICAL PROCESSES-REVISED

Source: Hodson, 1986 
DEFINITIONS OF THE PHONOLOGICAL PROCESSES USED IN

THE ASSESSMENT OF PHONOLGICAL PROCESSES (Hodson, 1986)

Consonant Sequence Reduction: occurs when a consonant in a sequence is deleted (e.g., /trig/ for "string").

Glides: occurs when $/ w /$ or $/ \mathrm{J} /$ are substituted with a non-glide phoneme (e.g., /pas/ for "wash") or omitted (e.g., /as/ for " wash").

Liquid (1): occurs when / $/$ / is omitted (e.g., /if/ for "leaf") or substituted by a non-liquid phoneme (e.g.,/wif/ for "leaf").

Liquid $(r)$ : occurs when $/ r, \gamma /$ is substituted by a nonliquid phoneme (e.g., /waIt/for "right") or omitted (e.g., /aIt/ for "right").

Nasals: occurs when nasal phonemes are omitted (e.g., /ouz/ for "nose") or substituted with a non-nasal phomeme (e.g., /pouz/ for "nose".

Postvocalic Singleton Consonant omission: occurs when a consonant that ends a syllable is deleted (e.g., /wa/ for "watch").

Prevocalic singleton Consonant omission: occurs when a consonant that initiates a syllable is deleted (e.g., /e i/ for "baby").

Stridents: occur when stridency is deleted from a word; it can be either from a deleted strident (e.g., /u/ for "shoe") or due to a substitution of a nonstrident phoneme in place of the correct strident phoneme (e.g., /tu/ for "shoe").

Syllable Reduction: occurs when a syllable is deleted in a multi-syllable word (e.g., /pe/ for "paper").

Velars: occur when either the velars $/ \mathrm{k} /$ or $/ \mathrm{g} /$ are omitted (e.g., /om/ for "comb") or substituted by a nonvelar phoneme (e.g., /tom/ for "comb"). 


\title{
APPENDIX B
}

PHONOLOGICAL PROCESS DEFINITIONS IN THE

KHAN-LEWIS PHONOLOGICAL ANALYSIS

\author{
Source: Khan \& Lewis, 1986
}


THE KHAN-LEWIS PHONOLOGICAL ANALYSIS

PHONOLOGICAL PROCESS DEFINITIONS (Khan \& Lewis, 1986)

DEVELOPMENTAL PHONOLOGICAL PROCESSES: normal developing processes.

Cluster Simplification: occurs when one or more members of a consonant sequence are deleted or when a schwa is inserted between them (e.g., /wino/ for "window").

Consonant Harmony: occurs when one consonant is affected by another consonant within the word and so both are produced at similar places of articulation (e.g., /p p/ for "cup").

Deaffrication: occurs when the stop feature of an affricate is deleted with the retention of the fricative feature (e.g., /mosiz/ for "matches").

Deletion of Final Consonants: occurs when the final consonant of the word is deleted (e.g., /ple/ for "plane").

Final Devoicing: occurs when the speaker produces a voiceless consonant for a voiced consonant in the final consonant (e.g., /bEt/ for "bed").

Initial Voicing: occurs when a voiced consonant is used in place of the correct voiceless consonant (e.g., /g^p/for "cup").

Liquid Simplification: either gliding of liquds (e.g., /bju/ for "blue") or vocalization of liquids (e.g., /snvo/ for "shovel").

Palatal Fronting: occurs when a speaker replaces a palatal consonant for a consonant in a more anterior portion of the mouth (e.g., /su/ for "shoe").

Stopping of Fricatives and Affricates: occurs when fricatives are replaced by affricates or stops, and when affricates are replaced by stops (e.g., /dIs/ for "this").

Stridency Deletion: occurs when the production of a strident consonant lacks stidency due to either deletion or replacement (e.g., /tu/ for "shoe").

Syllable Reduction: occurs when the speaker's production contains fewer syllables than the target word (e.g., /win/ for "window"). 
Velar Fronting: occurs when the speaker replaces a velar with a consonant located more anteriorly in the mouth than a velar, often occurs by replacing a velar with an alveolar (e.g., /tar/ for "carn).

NONDEVELOPMENTAL PHONOLOGICAL PROCESSES: those not characteristic of normal phonological development, but some normally developing children may apply them infrequently.

Backing to Velars: occurs when any consonant is replaced by a velar (e.g., /gkk/ for "bed").

Deletion of Initial Consonants: occurs when the initial consonant is deleted (e.g., /An/ for "gun").

Glottal Replacement: occurs when a consonant is replaced by a glottal stop (e.g., /mx?Iz/ for "matches"). 
APPENDIX C

PARENTAL CONSENT FORM 
Dear Parent/Guardian,

My name is Beverly Alexander. I am a graduate student at Portland state University in the field of Speech-Language Pathology. I am conducting a research project under the supervision of Mary Gordon, Associate Professor, concerning tests used to assess children who have speech sound disorders. I am attempting to determine the length of time it takes to administer and score various speech sound tests. The results of this study should help the clinician to utilize a more efficient means to assess chlldren with speech sound disorders.

I am searching for chlldren between the ages of 4 and 6 years to help with this research. If you and your child participate in this study, I would need to see $\mathrm{him} / \mathrm{her}$ on one occasion to do some testing. The testing would involve a brief hearing test and administration of three speech sound tests. This would take approximately one hour in the Portland state University Speech and Hearing Sciences Department. The testing would be completed by a Speech-Language Pathology graduate student.

Your child's name will not be used in reporting results. You may obtain your child's tests results from me. You will, of course, be free to withdraw your child from the study at any time without jeopardizing your relationship with Portland state University. There will be no charge for the evaluations.

If there are any guestions or problems regarding any aspect of this study, I may be reached at school (464-3533). Additionally, Mary Gordon, faculty thesis director, may be reached at the same number.

If you have any problems that are the result of your participation in this study, please contact the secretary of the Human Subjects Research and Review Committee, Office of Grants and Contracts, 303 Cramer Hall, Portland State University, 464-3417.

Please complete the attached approval sheet and return it in the self-addressed stamped envelope provided. If you indicate you are willing to participate, I will be contacting you within a few days by telephone to varify meeting times. 
Thank you for your help.

Beverly Alexander

Speech-Language Pathology

Master's student, PSU

I am interested in participating in your study.

I am not interested in participating in your study.

SI GNA TURE DATE :

CHILD'S NAME: BIRTHDATE:

ADDRESS :

PHONE

NUMBER : 
APPENDIX D

EXAMINER'S QUESTIONNAIRE 


\section{EXAMINER'S QUESTIONNAIRE}

The following questionnaire is designed to determine the eligibility of speech-language pathology graduate students for a study which will compare the administration and analysis times of phonetic and phonologic speech sound disorder tests. The results of this study should help the clinician to utilize a quicker and more efficient means of assessing children with speech sound disorders. Your participation in completing this questionnaire and possibly participating in this study is greatly

appreciated. This study will require approximately 4 to 5 hours of your time. Two to three hours will be spent administering tests at PSU and 2 to 3 hours will be spent analyzing the tests, which can be completed at your home. The study will be implemented at your convenience.

Thank You. Beverly Alexander

No. of YES NO Times

1. a. Have you ever administered the Photo Articulation Test (PAT)?

b. Have you ever scored the PAT?

c. If you answered "no" to (a)

or (b), have you received

formal instruction in the administration and analysis of the PAT during a PSU course within the last two years?

2. a. Have you ever administered the Assessment of Phonological Processes-Revised (APP)?

b. If you answered "no" to (a), have you received formal instruction in the administration of the APP during a PSU course within the last two years? 
3. a. Have you ever analyzed the

APP using the Computer

Analysis of Phonological

Processes (CAPP)?

b. If you answered "no" to (a),

have you received formal

instruction in the analysis

of the APP by using the CAPP

during a PSU course within

the last two years?

4. a. Have you ever administered

the Goldman-Fristoe Test of

Articulation (GFTA)?

b. Have you ever scored the GFTA?

c. If you answered "no" to (a)

or (b), have you received

formal instruction in the

administration and analysis

of the GFTA during a PSU

course within the last

two years?

5. a. Have you ever administered

the Khan-Lewis Phonological

Analysis (KLPA) (it is the

same as the sounds-in Words

subtest of the GFTA)?

b. Have you ever scored the

KLPA?

c. If you answered "no" to (a)

and (b), have you received

formal instruction in the

administration and analysis

of the GFTA during a PSU

course within the last

two years?

6. Are you interested in receiving clock hours during participation in this study?

7. If you are interested in participating in this study, please write your name and the telephone number where you can be reached during the summer, and then place this questionnaire in my box (Beverly Alexander) in the graduate room. Thanks again. 
APPENDIX E

OUTLINE OF INFORMATION COVERED IN TRAINING PERIOD 
OUTLINE OF INFORMATION COVERED IN TRAINING PERIOD

I. Administration and analysis procedures as listed in the test manuals

A. Photo Articulation Test (PAT)

B. Assessment of Phonological Processes (APP)

C. Khan-Lewis Phonological Analysis (KLPA)

D. Goldman-Fristoe Test of Articulation (GFTA)

E. Computer Analysis of Phonological Processes (CAPP)

II. Timing Procedures for the administration and analysis of each test as described in Appendix $F$
A. PAT
B. APP
C. KLPA
D. GFTA
E. CAPP

III. Materials given to the examiners

A. Test forms for each test (PAT, APP, KLPA, GFTA, and, CAPP).

B. Examiners timing procedures and instructions

C. Chart to record timed-results (Appendix I)

D. Outline of material to be covered in the training session. 
APPENDIX F

EXAMINER'S TIMING PROCEDURES AND INSTRUCTIONS 
EXAMINER'S TIMING PROCEDURES AND INSTRUCTIONS

\section{Administration}

1. Time the administration of each test separately, also time those subtests separately as listed on the "Chart to Record Timed Results" (Appendix I).

2. Begin timing of each test after all materials needed for testing are in place and child is sitting in his/her seat and prior to instructing the child.

3. If child needs a break in the middle of testing, stop the stop watch until he/she is seated again. Begin the stop watch when the child is back in his seat and you are ready to begin testing again.

4. The administration of each test will be the same as outlined in their manuals except:

a. When giving the GFTA write out the entire response phonetically on the sounds-in-Words subtest in order to be prepared to analyze the KLPA using this transcription.

5. In order to calculate the administration time of the KLPA, when giving the GFTA, calculate the time it takes to administer the sounds-in-Words subtest separately from the time it takes to administer the rest of the GFTA. When the Sounds-in-words subtest has been completed stop the stop watch and mark the time. Then restart the stop watch when you are ready to begin the next subtest.

6. When the last question, for each test has been answered by the subject, turn the stop watch off and record the time on the time recording sheet.

Analysis

1. Time the analysis of all tests separately, also time specific areas of each test separately which are 1 isted on the "Chart to Record Timed Results" (Appendix I).

2. When all materials needed to analyze the test are in front of you, start the stop watch.

3. If for any reason you are distracted or need a break in the middle of analyzing the test, stop the stop watch and restart the stop watch when you are seated and ready to begin analyzing the test again. 
4. The analysis of each test will be completed as outlined in their manuals, except:

a. The APP will be analyzed using the CAPP.

5. When you are satisfied that all of the responses have been analyzed, stop the stop watch and record the results on the recording sheet for each individual test.

6. When using the CAPP begin timing after the disc is in your hand, and before you turn the computer on. After the results are printed, and you have torn them off of the printer, turn the timer off and mark your time.

7. The analysis of all four tests should be completed within six weeks from the administration date.

8. Thank you. 


\section{APPENDIX G}

THE RECORDING FORM FOR THE

ASSESSMENT OF PHONOLOGICAL PROCESSES-REVISED

Source: Hodson, 1986 
77

THE ASSESSMENT OF PHONOLOGICAL PROCESSES - Revised

Barbara Williems Hodson

Name Birthdate Date Examiner

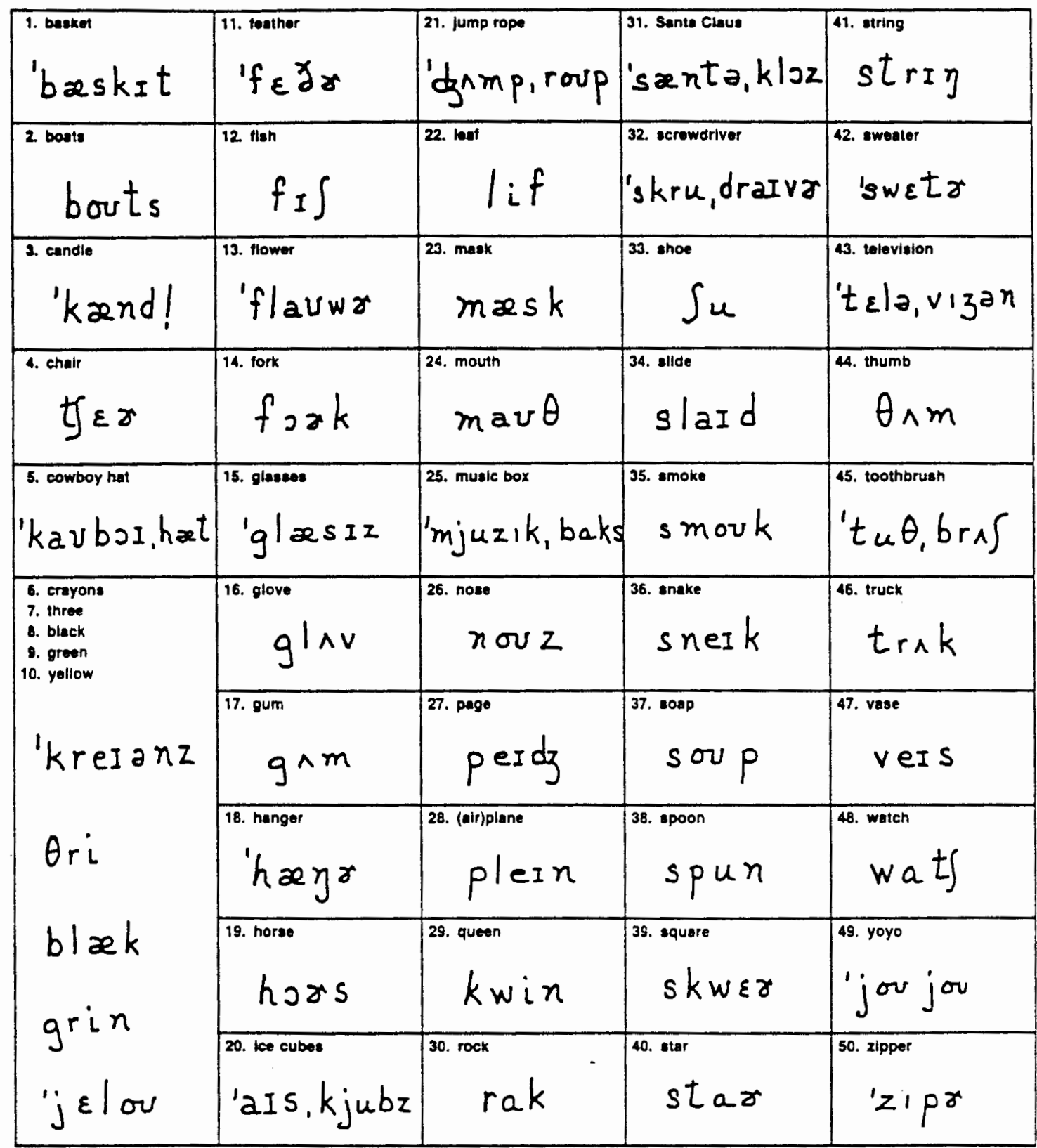

Copyrlgnt e 1986 by Adotional cooves of thes torm avedable in paos of 45 each trom:

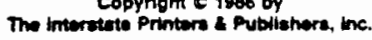

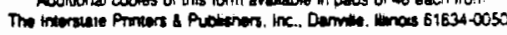
Puscer 10. 2632 
APPENDIX H

COMPUTER PRINT OUT OF THE COMPUTER ANALYSIS OF PHONOLOGICAL PROCESSES

Source: Hodson, 1985 
Name of Client:

Date of Birth: 1-3-84

Date of Phonological: 10-12-87

Age in Years: 3

Examiner's Name: Beverly Alexander

Diagnostic Information:

Phonological Analysis Summary

Pattern Deviations

Syllable Reduction

Prevocalic Singletons

Postvocalic singletons

Consonant Sequences

stridents

Velars

Liquid (1)

Liguid ( $r$ )

Nasals

Glides
Percentage of

occurrence

42

16

3

78

65

100

91

100

11

80

Average of Phonological Processes: 59

Phonological Deviancy Score: 22

Severity Interval: Severe

GOAL: To increase intelligibility by facilitating emergence of the following phonological patterns:

syllables

Consonant Sequences

stridents

Velars

Liquid (I)

Liquid ( $r$ )

Glides

COMPUTER ANALYSIS OE PHONOLOGICAL PROCESSES

Barbara Williams Hodson

Copyright 1985; Phonocomp 


\section{APPENDIX I}

CHART TO RECORD TIMED RESULTS 
CHART TO RECORD TIMED RESULTS

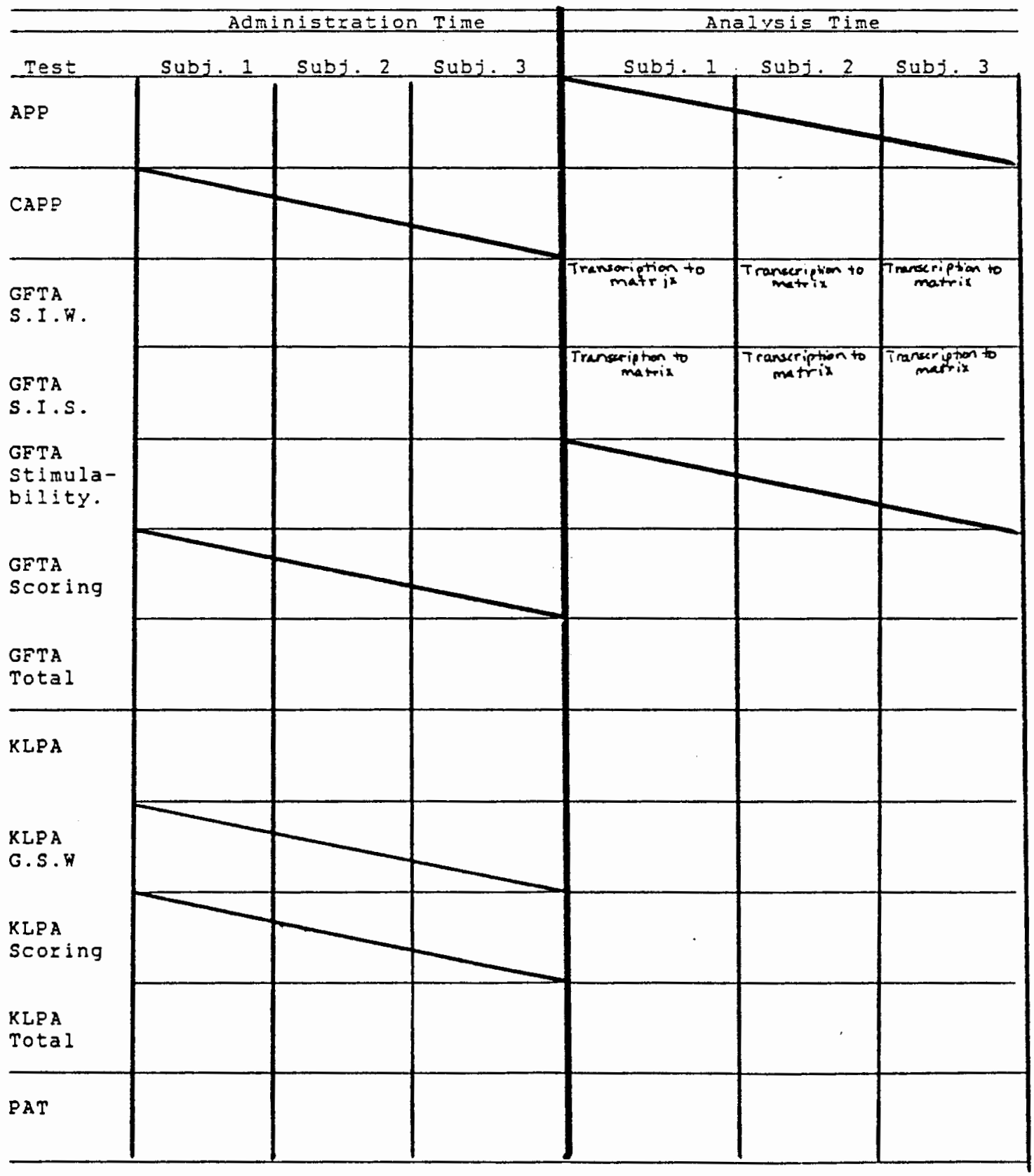

Assessment of Phonological Processes (APP)

Computer Assessment of Phonological Processes (CAPP)

Goldman-Fristoe Test of Articulation (GFTA)

Sounds-in-Words Subtest (S.I.W.)

Sounds-in-sentences subtest (S.I.S.)

Khan-Lewis Phonological Analys is (KLPA)

Goal Selection Worksheet (G.S.W.)

Photo Articulation rest (PAT) 
APPENDIX $J$

TOTAL OF THE ADMINISTRATION AND ANALYSIS TIMES FOR THE APP/CAPP, KLPA, GFTA, AND PAT 
TOTAL OF ADMINISTRATION AND ANALYSIS TIMES

APP AND CAPP

Administration Examiner 1

1. $11: 50(710)+$

2. $15: 34(934)$

3. $15: 24(924)+$

4. $13: 15(795)$

Analysis

Total

Severity

$+9: 29(569)=21: 19(1279)$ (mild)

$+10: 41(641)=26: 15(1575)$ (severe)

$+10: 38(638)=26: 02(1562)$ (severe)

Examiner 2

1. $14: 47(887)+12: 48(768)=27: 35$ (1655) (severe)

2. $12: 03(723)+8: 04(484)=20: 07$ (1207) (mild)

Examiner 3

1. $12: 09(729)+6: 43(403)=18: 52$ (1132) (mild)

2. $12: 44(764)+13: 38(818)=26: 22$ (1582) (moderate)

Examiner 4

1. $11: 12(672)+7: 16(436)=18: 28$ (1108) (moderate)

2. $12: 40(760)+9: 45(585)=22: 25$ (1345) (mild)

Examiner 5

1. $16: 03(963)+10: 12(612)=26: 15$ (1575) (moderate)

2. $8: 49(529+8: 31(511)=17: 20$ (1040) (moderate) 
KLPA WITHOUT TRANSCRIPTION

Administration

Analys is

Tota 1

Examiner 1

1. $6: 58(418)+16: 21(981)=23: 19$ (1399)

2. $6: 41(401)+34: 47(2087)=41: 28(2488)$

3. $6: 35(395)+35: 23(2123)=41: 58(2518)$

4. $6: 59(419)+34: 17(2057)=41: 16(2476)$

Examiner 2

1. $9: 45(585)+43: 16(2596)=53: 01(3181)$

2. $5: 00(300)+17: 11(1031)=22: 11(1331)$

Examiner 3

1. $8: 27(507)+16: 13(973)=24: 40(1480)$

2. $7: 48(468)+15: 10(910)=22: 58(1378)$

Examiner 4

1. $6: 52(412)+45: 31(2731)=52: 23(3143)$

2. $5: 59(359)+29: 05(1745)=35: 04(2104)$

Examiner 5

1. $7: 07(427)+37: 14(2234)=44: 21(2661)$

2. $11: 30(690)+34: 58(2098)=46: 28(2788)$

KLPA WITH TRANSCRIPTION

Administration

Examiner 1

1. $6: 58(418)$

2. $6: 41(401)+40: 10(2410)=46: 51$ (2811)

3. $6: 35(395)+41: 47(2507)=48: 22(2902)$

4. $6: 59(419)+40: 57(2457)=47: 56(2876)$

Examiner 2

1. $9: 45(585)+48: 20(2900)=58: 05(3485)$

2. $5: 00(300)+20: 24(1224)=25: 24(1524)$

Examiner 3

1. $8: 27(507)+21: 36(1296)=30: 03$ (1803)

2. $7: 48(468)+23: 09(1389)=30: 57(1857)$

Examiner 4

1. $6: 52(412)+53: 49(3229)=60: 41(3641)$

2. $5: 59(359)+32: 21(1941)=38: 20(2300)$

Examiner 5

1. $7: 07(427)+44: 40(2680)=51: 47(3107)$

2. $11: 03(690)+42: 10(2530)=53: 40(3220)$ 
GFTA

Administration Analysis Total

Examiner 1

1. $17: 23(1043)+5: 50(350)=23: 13(1393)$

2. $18: 40(1120)+1047(647)=29: 27(1767)$

3. $19: 11(1151)+7: 49(469)=27: 00(1620)$

4. $17: 45(1065)+7: 23(443)=25: 08$ (1508)

Examiner 2

1. $24: 07(1487)+7: 34(454)=32: 21$ (1941)

2. $15: 57(957)+2: 38(158)=18: 35$ (1115)

Examiner 3

1. $15: 49(949)+11: 38(698)=27: 27(1647)$

2. $18: 04(1084)+5: 14(314)=23: 18(1398)$

Examiner 4

1. $20: 55(1255)+7: 57(477)=28: 52(1732)$

2. $15: 56(956)+4: 01(241)=19: 57$ (1197)

Examiner 5

1. $22: 16(1336)+6: 25(385)=28: 41(1721)$

2. $24: 27(1467)+6: 18(378)=30: 45(1845)$

PAT

Administration Analysis Total Examiner 1

1. $7: 25(445)+23=7: 48(468)$

2. $11: 52(712)+39=12: 31(751)$

3. $11: 51(711)+44=12: 35(755)$

4. $10: 16(616)+25=10: 41(641)$

Examiner 2

1. $12: 48(768)+21=13: 06(789)$

2. $10: 27(627)+46=11: 13(673)$

Examiner 3

1. $8: 59(507)+30=9: 29(537)$

2. $10: 43(643)+33=11: 16(676)$

Examiner 4

1. $11: 12(672)+45=11: 57(717)$

2. $8: 31(511)+25=8: 56(536)$

Examiner 5

1. $12: 18(738)+23=12: 41(761)$

2. $15: 13(913)+23=15: 36(936)$ 